\title{
From $m^{6} A$ to cap-adjacent $m^{6} A m$ and their effects on mRNAs.
}

\author{
Trinh T. Tat ${ }^{1,2,3,8}$, and Daniel L. Kiss ${ }^{1,2,4,5,6,7,8 \#}$
}

\section{Author affiliations}

1 Department of Cardiovascular Sciences,

2 RNA Therapeutics Program,

3 orcid.org/0000-0002-6419-8007

4 Houston Methodist Cancer Center,

5 Weil Cornell Medical College,

6 Houston Methodist Academic Institute,

7 orcid.org/0000-0001-5033-7160

86670 Bertner Ave, Houston, TX 77030 USA

\# To whom correspondence should be addressed:

Daniel L. Kiss, Ph.D.

Houston Methodist Research Institute

6670 Bertner Ave

R10-212

Houston, TX 77030 USA

Email: dlkiss@houstonmethodist.org 


\section{Table of Contents}

1. The epitranscriptome: dynamic RNA modifications that regulate gene expression

1.1 An introduction to common RNA modifications

1.2 Methylated RNA bases

1.3 Focus and scope of this chapter

2. The $m^{7} G$ cap and its role in the regulation of mRNAs

3. N6-methyladenosine $\left(m^{6} \mathrm{~A}\right)$

$3.1 \mathrm{~m}^{6} \mathrm{~A}$ writers

$3.2 \mathrm{~m}^{6} \mathrm{~A}$ readers

$3.3 \mathrm{~m}^{6} \mathrm{~A}$ erasers

3.4 The effects of $m^{6} \mathrm{~A}$ on mRNA

4. Cap-adjacent $\mathrm{m}^{6} \mathrm{Am}$.

4.1 PCIF1, the writer of cap-adjacent $\mathrm{m}^{6} \mathrm{Am}$

4.2 FTO, an $\mathrm{m}^{6} \mathrm{Am}$ eraser

4.3 Functions of $\mathrm{CA}-\mathrm{m}^{6} \mathrm{Am}$

4.3.1 The effects of CA- ${ }^{6} A m$ on decapping 4.3.2 The effect of $C A-m^{6} A m$ on mRNA levels

4.3.3 The translation of CA-m ${ }^{6} \mathrm{Am}$-bearing mRNAs

5. Unanswered questions regarding cap-adjacent $m^{6} A m$

5.1 Is $\mathrm{CA}-\mathrm{m}^{6} \mathrm{Am}$ addition by PCIF1 truly a co-transcriptional event?

5.2. Could PCIF1 function in concert with cytoplasmic capping?

6. Closing remarks

7. Acknowledgements

References 


\begin{abstract}
Although RNA modifications were discovered decades ago, the identification of enzymes that write, read, and erase RNA modifications enabled their functional study and spawned the field of epitranscriptomics. Coupling that knowledge to new methods has enabled the precise pinpointing of epitranscriptomic modifications across the transcriptome plus the elucidation of their functional consequences. PCIF1 (Phosphorylated $\underline{C} T D$ Interacting Factor 1) was shown to add N6, 2'-O-dimethyladenosine $\left(m^{6} \mathrm{Am}\right)$ marks at the first nucleotide after the $5^{\prime}$ N7-methylguanosine $\left(\mathrm{m}^{7} \mathrm{G}\right)$ cap. In this review, we discuss the epitranscriptomic regulation of $m R N A$ in general, and focus on $m^{7} G$ cap-adjacent $m^{6} \mathrm{Am}$ in particular. $m^{6} \mathrm{Am}$ positions can now be distinguished from N6-methyladenosine $\left(\mathrm{m}^{6} \mathrm{~A}\right)$ using new techniques leveraging PCIF1-knockout cells. Although $\mathrm{m}^{6} \mathrm{Am}$ modification sites can be detected precisely, conflicting data have been published regarding how capadjacent $\mathrm{m}^{6} \mathrm{Am}$ marks affect their host mRNA. Discrepancies in the data mean that the effects of cap-adjacent $\mathrm{m}^{6} \mathrm{Am}$ on mRNA stability, decapping, and translation continue to be debated. Finally, while PCIF1 is predominantly nuclear, a subset of results suggest a possible cytoplasmic role as well. Taken together, these contradictory results which employed different methodologies and cell lines means that further experiments are required to determine the ultimate biological function(s) of $m^{7} G$ cap-adjacent $m^{6} \mathrm{Am}$.
\end{abstract}

\title{
Key words:
}

Epitranscriptome, PCIF1, N6, 2'-O-dimethyladenosine, cap-adjacent $\mathrm{m}^{6} \mathrm{Am}$, cytoplasmic capping 


\section{The epitranscriptome: dynamic RNA modifications that regulate gene expression}

\subsection{An introduction to common RNA modifications}

The discovery of pseudouridine as the first structurally modified RNA nucleoside in the 1950s began over two decades of rapid advances where many chemically modified nucleotides were identified for the first time [1-3]. To date, about 160 distinct RNA modifications are cataloged in the MODOMICS (http://genesilico.pl/modomics/) database and map to many different types of cellular RNAs [3-11]. Decades of data show that RNA modifications are common in ribosomal $\underline{\mathrm{RNA}}$ (rRNA), transfer RNA (tRNA), small nuclear RNA (snRNA), small nucleolar RNA (snoRNA) and messenger RNA (mRNA) among other RNA types [11-21]. As tRNAs, snRNAs, snoRNAs, and rRNAs are both abundant and heavily (and specifically) modified in cells, RNA modifications were always of great interest in these fields [7, 22, 23]. In fact, the proper modification of key nucleotides is critical to the functions of many of these non-coding RNAs (ncRNA) [5, 7, 24, 25]. Compared to those ncRNAs, apart from the cap structures, mRNA base modifications were significantly understudied until $\sim 10-15$ years ago [3-6, 26-28]. To harness this growing interest, 'RNA epigenetics' was suggested name to describe the growing field focused on the study of RNA modifications [3]. Shortly thereafter, the field adopted epitranscriptomics as a more distinct RNA-focused identifier $[4,6,10]$.

Several key advances have driven the growing interest in epitranscriptomics, mainly by removing barriers to their study. The first barrier fell when it was clear that noncap-associated epitranscriptomic marks, including those on mRNAs, were both dynamic and had functional consequences [7, 29-31]. The continuing identification of the enzymes that added, interpreted and removed epitranscriptomic marks also proved key [30-34]. Finally, the coupling of deep sequencing strategies with biochemical methods to purify modified RNAs yielded multiple methods that can recognize and pinpoint both the presence and prevalence of a diverse set of mRNA modifications [35-38]. Table 1 presents the existing methodologies that target the three key RNA modifications at the focus of this chapter. [35-37]. Importantly, third generation long read sequencing technologies promise the next revolution in epitranscriptomics [37, 39-42]. For example, RNA modifications can now be detected directly on their RNAs without using reverse 
transcription via direct RNA sequencing from Oxford Nanopore and similar methods are being designed to leverage PacBio long read sequencing as well [37, 39-42].

Table 1: Transcriptome-wide methods that target and map m6A, m6Am, and $\mathrm{m7G}$ capping sites

\begin{tabular}{|c|c|c|}
\hline RNA modification & Technique & Reference \\
\hline all RNA modifications & $\begin{array}{c}\text { Oxford Nanopore direct RNA } \\
\text { sequencing }\end{array}$ & [43] \\
\hline \multirow{3}{*}{$m^{7} G$} & $m^{7} G-M a P-s e q$ & [44] \\
\hline & AlkAniline-Seq & [45] \\
\hline & $\begin{array}{l}\text { Capped Analysis of Gene } \\
\text { Expression (CAGE) }\end{array}$ & [46] \\
\hline \multirow{2}{*}{$\mathrm{m}^{6} \mathrm{Am}$} & $\mathrm{m}^{6} \mathrm{Am}-\mathrm{Exo}-\mathrm{Seq}$ & [47] \\
\hline & $m^{6}$ ACE-seq & [48] \\
\hline \multirow{10}{*}{$\begin{array}{c}\mathrm{m}^{6} \mathrm{~A}, \\
\text { (most also detect } \\
\mathrm{m}^{6} \mathrm{Am} \text { ) }\end{array}$} & $m^{6} A-s e q$ & [49] \\
\hline & meRIP-seq & [10] \\
\hline & $m^{6}$ A-LAIC-seq & [50] \\
\hline & miCLIP-seq & [51] \\
\hline & PA- ${ }^{6}$ A-seq & [52] \\
\hline & $m^{6} \mathrm{~A}-\mathrm{CLIP}$-seq & [53] \\
\hline & $\mathrm{m}^{6} \mathrm{~A}$-label-seq & [54] \\
\hline & $m^{6} \mathrm{~A}-\mathrm{SEAL}-\mathrm{seq}$ & [55] \\
\hline & MAZTER-seq & [56] \\
\hline & $m^{6} A-R E F-s e q$ & [57] \\
\hline
\end{tabular}

\subsection{Methylated RNA bases}

One of the most common family of RNA modifications is methylation, which is ubiquitous in life [35, 58-60]. In fact, according to the MODOMICS database, roughly 100 of the $\sim 160$ known modified RNA bases include at least one type of methylation event among the modifications [8,9]. RNA methylation predominantly occurs on nitrogen and carbon positions and/or amine groups outside the ring of purine and pyrimidine bases, plus the oxygen atom of the 2'-OH moiety of the ribose sugar [8,9]. Several types of methylated base modifications are common in eukaryotic mRNA. The $m^{7} G$ (N7methylguanosine) that constitutes the 5' cap structure of mRNAs was among the first base modifications to be identified and characterized on mRNAs [13,16, 19, 61]. Besides the $m^{7} G$ cap, $m^{6} A$ (N6-methyladenosine) and $m^{6} \mathrm{Am}$ (N6,2'-O-dimethyladenosine) are two of the better characterized RNA methylation events (see section 3, Figure 3.1, and section 4, Figure 4.1) and were also identified as abundant in mRNAs in the mid 1970's 
$[12,14-17,21,29,62-74]$. The second of these, $m^{6} A m$, is common in the bodies of certain ncRNAs such as snRNAs, and enriched directly adjacent to 5' mRNA caps and imparts distinct functional properties to the mRNA [25, 26, 29, 51, 67-76].

Apart from the $\mathrm{m}^{7} \mathrm{G}$ cap, $\mathrm{m}^{6} \mathrm{~A}$, and $\mathrm{m}^{6} \mathrm{Am}$ RNA modifications which will be covered in detail in sections 2-4 below, several other methylated RNA bases are common [7-9]. These include $\mathrm{m}^{5} \mathrm{C}$ (5-methylcytosine), $\mathrm{m}^{1} \mathrm{~A}$ (N1-methyladenosine), $\mathrm{m}^{6,6} \mathrm{~A}$ (N6, N6dimethyladenosine), $\mathrm{hm}^{5} \mathrm{C}$ (5-hydroxymethylcytosine), and the TMG (N2, N2, N7 trimethylguanosine) cap among many others [3, 7-9, 77-81]. These epitranscriptomic marks are known to play vital roles in altering RNA - protein interactions, RNA secondary structures, and causing changes in RNA stability and/or translation efficiency [4, 6, 7, 35, 59, 80, 82]. The TMG cap is found on snRNAs, snoRNAs and certain other ncRNAs [80]. $\mathrm{m}^{1} \mathrm{~A}$ modification is found mainly in tRNAs, mRNAs, long non-coding RNAs (IncRNAs), and mitochondrial genes [24]. In 2017, $\mathrm{m}^{1} \mathrm{~A}$ was mapped near the transcription start sites (TSS) and the first splice site in coding sequences and shown to increase translation efficiency through enabling the non-canonical binding of the exon-exon junction complex at the 5' untranslated region (UTR) [83]. In addition, the methyl group of $\mathrm{m}^{1} \mathrm{~A}$ is known to block Watson-Crick base pairing and effectively terminates reverse transcription and disrupts translation [83]. Similar to $\mathrm{m}^{1} \mathrm{~A}, \mathrm{~m}^{5} \mathrm{C}$ sites are mapped in human mRNA and IncRNA species, however, $\mathrm{m}^{5} \mathrm{C}$ sites are mainly enriched in the 5' UTRs before translation initiation sites, and in close proximity to the translation stop codon [7, 24, 84]. Changes in the level of NSUN2, a key $\mathrm{m}^{5} \mathrm{C}$ methyl-transferase have been shown to strongly affect RNA metabolism; and are linked to various human neurodegenerative diseases and cancers [24, 85-88].

\subsection{Focus and scope of the paper}

Taken together, the abundance, sequence context, and chemical structures of RNA modifications create the epitranscriptomic landscape which can drive both molecular and cellular dynamics. We are now beginning to better understand key modifications in epitranscriptome and have begun unraveling their regulatory roles in biological processes of cells. Further, advances are continuously providing new precise, sensitive, and 
quantitative experimental and computational techniques to identify, pinpoint, and map individual epitranscriptomic modifications with single base resolution [36].

In this review, we focus on three RNA modifications the $m^{7} G$ cap, $m^{6} A$, and $m^{6} A m$ and their effects on mRNA half-life and translation. We compare and contrast the "knowns" and "unknowns" regarding $\mathrm{m}^{6} \mathrm{~A}$, and $\mathrm{m}^{6} \mathrm{Am}$ in particular. Table 1 lists the common techniques that are used to target the three epitranscriptomic marks described below [36]. As a detailed description of these methodologies is beyond the scope of this chapter, please see these recent comprehensive reviews for more information [36]. Finally, as this review focuses on $m^{7} G$ cap-adjacent $m^{6} A m$ marks on mRNAs and internal

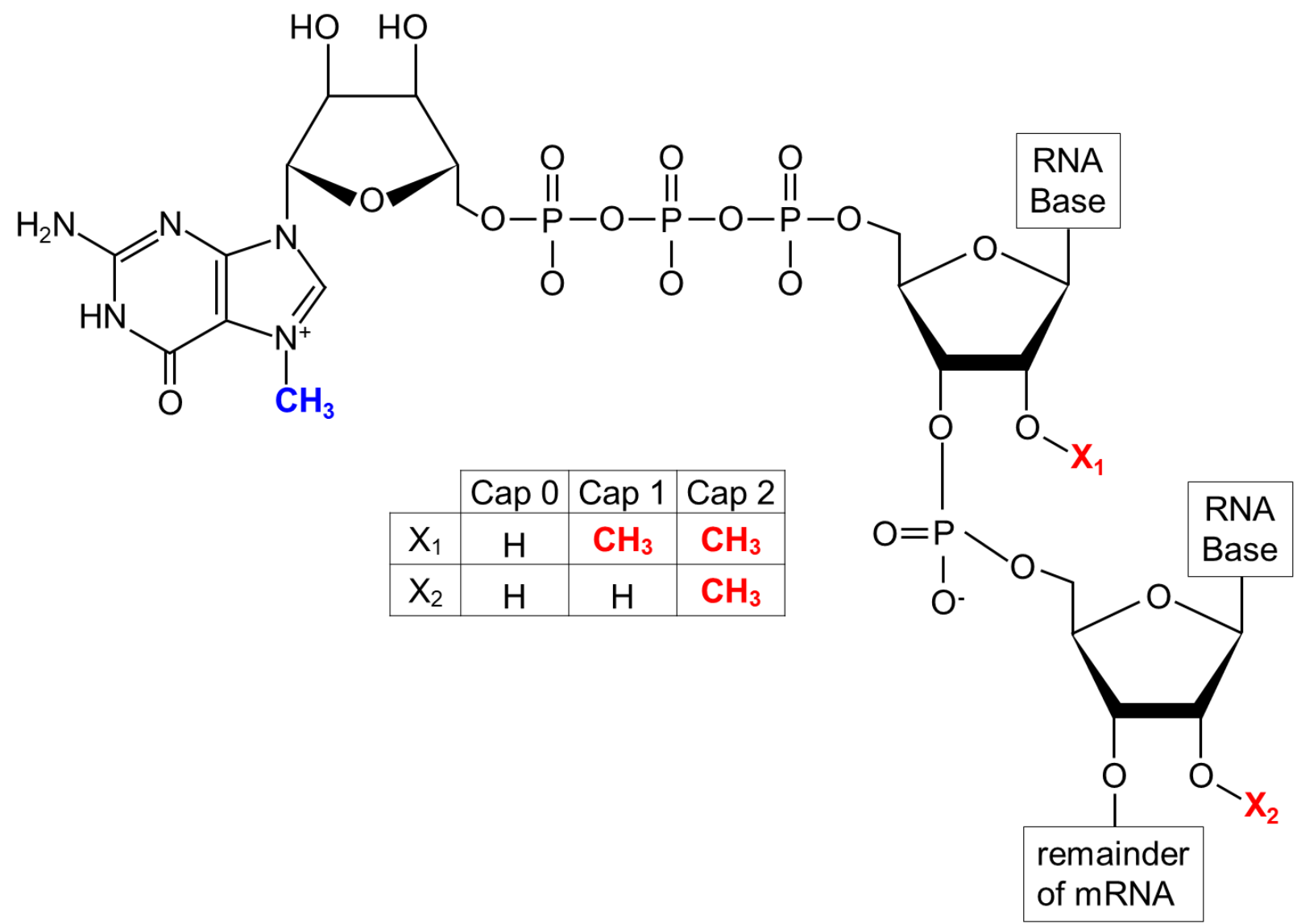

$m^{6} \mathrm{Am}$ marks are well documented for $\mathrm{U} 2$ snRNA and can be added to certain mRNAs under certain conditions, we will abbreviate $m^{7} G$ cap-adjacent $\underline{m^{6} A m}$ as $C A-m^{6} A m$ hereafter $[25,89]$.

Figure 2.1: A diagram showing the chemical structures of different cap structures observed in eukaryotes. Critical features of the cap structure include: the methylation 
on the $\mathrm{m}^{7} \mathrm{G}$-cap (Blue) and possible methylations on the first $\left(\mathrm{X}_{1}\right)$ and second $\left(\mathrm{X}_{2}\right)$ transcribed nucleotides (Red). Cap 0 RNAs lack methyl groups at both $X_{1}$ and $X_{2}$, Cap 1 RNAs have methyl groups on $X_{1}$, but not $X_{2}$, while Cap 2 RNAs have methyl groups on both nucleotides (inset table).

\section{The $m^{7} G$ cap and its role in the regulation of mRNAs}

Likely because of its presence at the 5' end of every RNA polymerase IItranscribed mRNA, the $m^{7} G$ cap structure (Figure 2.1) was among the first RNA modifications with a clearly-defined function $[13,20,90,91]$. The $\underline{R N A}$ guanylyltransferase and 5'-triphosphatase (RNGTT) uses a two-step process to add an inverted guanosine residue to the initiating nucleotide of the nascent mRNA via a 5'-5' triphosphate linkage $[19,20]$. This occurs co-transcriptionally in the nucleus as the nascent RNA is extruded from RNA Polymerase II as it transcribes mRNAs [20, 92-94]. The final step of cap maturation occurs when RNA guanine-7 methyltransferase (RNMT) adds a methylation onto the $\mathrm{N} 7$ position of the inverted guanosine to complete the $\mathrm{m}^{7} \mathrm{G}$ cap (Figure 2.1, blue) [92, 93, 95]. This methyl group is a crucial feature and protects the mRNA from degradation and enhances mRNA translation [96-99]. Notably, studies in the past decade have demonstrated that functional pools of RNGTT and RNMT are present in the cytoplasm, and that a subset of uncapped human mRNAs can also be capped and methylated in the cytoplasm [27, 74, 100-102].

Other early works also demonstrated that in addition to the $\mathrm{m}^{7} \mathrm{G}$ cap, one or both of the first two transcribed nucleotides of an mRNA also modified in some organisms [12$21,61-65,69,71,103]$. Together with the $m^{7} G$ cap mRNA were said to have Cap 0, Cap 1 or Cap 2 (Figure 2.1) depending upon whether zero, one, or two transcribed RNA bases were methylated $[17,62,66]$. These methylations at the 2' position on the ribose sugar of the first transcribed nucleotide are added in the nucleus by the actions of mRNA cap 2 -O-methyltransferase, the first of which was identified in vaccinia virus [104, 105]. In humans, the final methylation to complete Cap 2 structures is added in the cytoplasm by hMTr2 [106]. The prevalence of these distinct mRNA cap structures depends on the organism, but in general, Cap 0 structures are present in lower eukaryotes, while Cap 1 and Cap 2 structures are more prevalent in more advanced eukaryotes [90-93, 107]. 
Notably different organisms such as trypanosomes often generate hypermethylated Cap 3 and Cap 4 structures where the third and fourth bases of their mRNAs are also
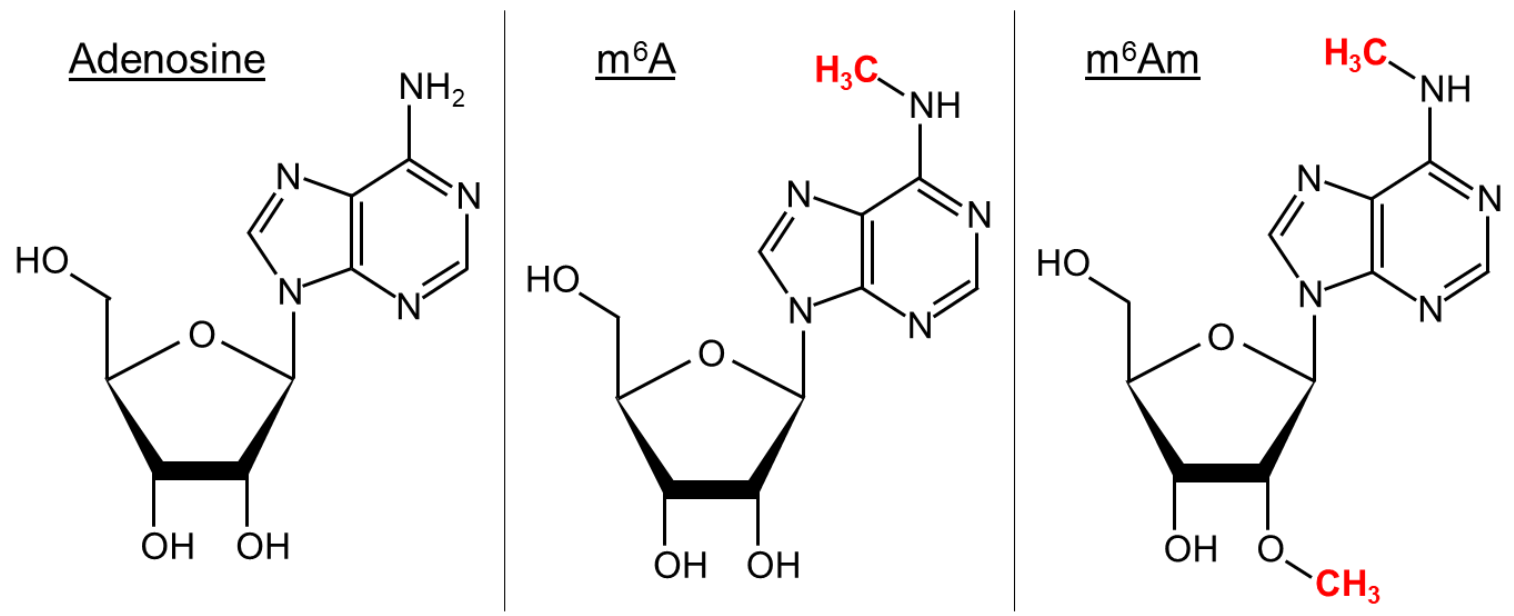

methylated $[108,109]$. Cap 0 structures are essential to protect the mRNA from nucleases and are also required to enable efficient translation of mRNAs [92, 93]. Cap 1 and Cap 2 structures have been shown to be critical in designating an mRNA as 'self' to escape the cellular innate immune response in humans $[92,93,107]$.

Figure 3.1: Diagrams showing the chemical structures of Adenosine, $m^{6} A$, and $\mathbf{m}^{6} \mathbf{A m}$. The added methyl groups are highlighted in red on modified bases.

\section{N6-methyladenosine $\left(\mathrm{m}^{6} \mathrm{~A}\right)$}

As discussed above, N6-methyladenosine $\left(\mathrm{m}^{6} \mathrm{~A}\right)$ and N6, 2'-O-dimethyladenosine $\left(m^{6} \mathrm{Am}\right)$ are comparatively abundant RNA modifications (Figure 3.1 ) in polyadenylated (poly(A)) mRNAs. Early works using $\mathrm{P}^{32}$-labeled cellular RNA, nucleases, and thin-layer chromatography showed that $\mathrm{m}^{6} \mathrm{~A}$ was the most abundant internal mRNA modification and estimated that $\mathrm{m}^{6} \mathrm{~A}$ and comprised $\sim 0.125 \%$ of all bases in poly $(\mathrm{A})$ mRNA $[62,65]$. Those data were bolstered as $\mathrm{m}^{6} \mathrm{~A}$ was determined to comprise roughly one in every $\sim 800$ nucleotides in poly (A)-selected RNA species from both the cytoplasm and the nucleus [63]. They also showed that $\mathrm{m}^{6} \mathrm{~A}$ occurs roughly once in every $1800-3000$ nucleotides, in non-polyadenylated, non-ribosomal RNAs [63]. The first consensus sequence motif candidates for $\mathrm{m}^{6} \mathrm{~A}$ addition were identified when $\sim 70 \%$ of $\mathrm{m}^{6} \mathrm{~A}$ modifications were shown to occur in the context of $G\left(m^{6} A\right) C$ trinucleotides and that the remaining $30 \%$ occurred in $A\left(m^{6} A\right) C$ trinucleotides $[59,110,111]$. Finally, the increased 
prevalence of $\mathrm{m}^{6} \mathrm{~A}$ with a particular mRNA correlated with RNA instability [29]. Although the identities, relative frequency, sequence context, and general effect of $m^{6} A m R N A$ modifications were known since the 1970's, they remained difficult to study as methods to definitively map their positions were limited to the extreme 5' ends of mRNAs.

Advances in high-throughput sequencing technologies coupled to the advent of new biochemical reagents that target $\mathrm{m}^{6} \mathrm{~A}$ bases have allowed many groups to revisit and expand upon these early estimates. These methods (Table 1 ) now estimate that $\mathrm{m}^{6} \mathrm{~A}$ comprises about $0.2 \%-0.6 \%$ of all adenosines in mammalian mRNAs [10, 26, 36-38, $49,52,112]$. Furthermore, they can provide a degree of certainty, with some methods offering single base resolution, as to where these mRNA modifications occur in the mRNA $[10,26,36-38,49,50,52-55,57,112]$. Transcriptome-wide studies have convincingly shown that $\mathrm{m}^{6} \mathrm{~A}$ was enriched both near the stop codon and in 3 ' UTRs of mammalian mRNAs [10, 26, 36-38, 49, 52, 112]. Despite this progress, new methods which can more precisely verify the presence and positioning of $\mathrm{m}^{6} \mathrm{~A}$ modifications will continue to be in high demand.

The most consequential advances to define the function(s) of $\mathrm{m}^{6} \mathrm{~A}$ in vivo were made when the enzymes involved in adding and surveying $\mathrm{m}^{6} \mathrm{~A}$ were identified and characterized [32]. The cellular factors that place, interpret and remove epitranscriptomic marks are generally referred to as writers, readers, and erasers respectively. In this chapter, we discuss the effectors including writers, readers, and erasers of $\mathrm{m}^{6} \mathrm{~A}$, and $\mathrm{m}^{6} \mathrm{Am}$.

\section{$3.1 \mathrm{~m}^{6} \mathrm{~A}$ writers}

Initially named MT-A, methyltransferase-like protein $\underline{3}$ (METTL3) was the first $\mathrm{m}^{6} \mathrm{~A}$ writer to be identified [32]. Before the identification and cloning of METTL3, previous works had demonstrated that METTL3 was part of a multi-protein complex [33, 34]. In fact, the efforts of multiple groups have shown that the $\mathrm{m}^{6} \mathrm{~A}$ methyltransferase complex consisting of METTL3, methyltransferase-like protein $\underline{14}$ (METTL14), Wilms tumor 1-

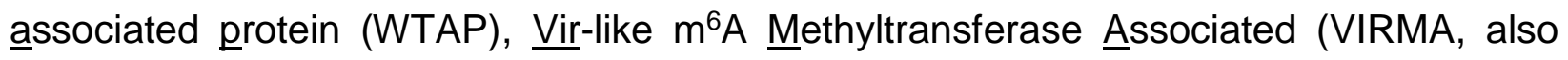
called KIAA1429), and ㅌNA Binding Motif Protein $\underline{15}$ (RBM15)/RBM15B are responsible for depositing $\mathrm{m}^{6} \mathrm{~A}$ in a co-transcriptional manner $[32-35,59,113]$. 
The majority of $\mathrm{m}^{6} \mathrm{~A}$ mRNA methylations are situated co-transcriptionally by methyltransferase writer complexes in a $\mathrm{DRACH}(\mathrm{D}=\mathrm{A}, \mathrm{G}$, or $\mathrm{U}, \mathrm{R}=\mathrm{A}$ or $\mathrm{G}, \mathrm{H}=\mathrm{A}, \mathrm{C}$, or $U$ ) sequence context $[35,114,115]$. Although METTL3 contains a nuclear localization signal (NLS), it is distributed distinctly among different cell lines [116]. METTL3 localizes predominantly within the nucleus, with a visible enrichment in nuclear speckles where it interacts with WTAP to form of a stable dimer with METTL14 in HeLa cells [59]. A fraction of METTL3 is associated with the promoter regions of $\sim 80$ active genes marked by CEBPZ, independent of METTL14, suggesting a transcript-specific $\mathrm{m}^{6} \mathrm{~A}$ methylation activity [117]. The recruitment of METTL3 to discrete chromatin loci in response to stress is dynamic, possibly via the action of epigenetic marks and/or transcription factors, [87]. Furthermore, H3K36me3, a gene-body enriched histone modification, was shown to recruit METTL3 through interactions with METTL14 to deposit $\mathrm{m}^{6} \mathrm{~A}$ predominantly within mRNA open reading frames and 3' UTRs [118].

Although the majority of METTL3 is found in the nucleus, it has been detected in the cytoplasm of several human cell lines and its cytoplasmic function(s) remains unknown [119]. One possibility is that post-translational modifications change the interactions between METTL3 and its interactome leading to METTL3's cytoplasmic localization $[59,119]$. It is possible that cytoplasmic METTL3 is not an $\mathrm{m}^{6} \mathrm{~A}$ writer, but rather functions as an $\mathrm{m}^{6} \mathrm{~A}$ reader [120]. Using lung cancer cells, cytoplasmic METTL3 promoted the translation of a reporter mRNA when tethered to its 3' UTR [120]. Through post-translational modifications (such as SUMOylation) and interactions with other associated proteins, METTL3 could affect protein instability, localization, and the formation and catalytic activity of $\mathrm{m}^{6} \mathrm{~A}$ writer complexes [59].

Another $\mathrm{m}^{6} \mathrm{~A}$ writer, methyltransferase-like protein $\underline{16}$ (METTL16), has a more restricted list of substrates including the hairpin (hp1) in the 3' UTR of human methionine adenosyltransferase $2 \mathrm{~A}$ mRNA (MAT2A) that encodes the S-adenosylmethionine synthetase and the U6 snRNA [121-129]. As with METTL3, at least a portion of METTL16 protein localizes to the cytoplasm [129]. In addition, Ma et al. recently showed that ZCCHC4 is $\mathrm{m}^{6} \mathrm{~A}$ writer that methylates the A4220 on 28S rRNA, as well as interacts with a small group of mRNAs [130]. 


\section{$3.2 \mathrm{~m}^{6} \mathrm{~A}$ readers}

Several methods including the immunoprecipitation or pull down of methylated probes and quantitative protein mass spectrometry have been used to identify multiple $\mathrm{m}^{6} \mathrm{~A}$ readers [38]. The first family of $\mathrm{m}^{6} \mathrm{~A}$ reader proteins contain YT521-B homology (YTH) domains, including the $\underline{\mathrm{YTH}}$ domain family $\underline{1-3}$ (YTHDF1-3) and $\underline{\mathrm{YTH}}$ domain containing 1-2 (YTHDC1-2) proteins in humans [131-134]. Although belonging to the same broader protein family, several YTH domain-containing proteins have opposing effects when they recognize mRNAs with $\mathrm{m}^{6} \mathrm{~A}$ marks $[38,59]$. For example, cytoplasmic YTHDF2 promotes mRNA deadenylation and degradation by recruiting deadenylase complexes [7]. Two other $\mathrm{m}^{6} \mathrm{~A}$ readers, YTHDF1 and YTHDF3, promote the translation of $\mathrm{m}^{6} \mathrm{~A}$-containing $\mathrm{mRNAs}$ by recruiting translation initiation factors in HeLa cells [134136]. YTHDC2 also regulates both mRNA stability and translation, in addition to playing an important role in spermatogenesis [137]. Finally, YTHDC1 localizes to the nucleus and helps regulate mRNA splicing, promotes mRNA export, and accelerates the decay of certain transcripts [136].

Another group of $\mathrm{m}^{6} \mathrm{~A}$ readers have common $\underline{\mathrm{R} N A}$ binding domains (RBDs) such as arginine/glycine-rich (RGG) domains, $\underline{R} N A$ recognition motifs (RRM), and $\underline{K}$ homology $(\mathrm{KH})$ domains, to preferentially bind $\mathrm{m}^{6} \mathrm{~A}$-containing RNAs [138]. Having one RGG domain and three $\mathrm{KH}$ domains, Fragile $\mathrm{X}$ mental retardation 1 (FMR1) recruits YTHDF2 to affect the translation and stability of $\mathrm{m}^{6} \mathrm{~A}$-containing mRNAs [114]. Several other $\mathrm{m}^{6} \mathrm{~A}$ readers such as insulin-like growth factor $\underline{2}$ mRNA-binding proteins 1-3 (IGF2BP1-3) or proline rich coiled-coil $\underline{2 A}$ (Prrc2a), which have been reported to recognize and stabilize $\mathrm{m}^{6} \mathrm{~A}$-bearing mRNAs [115]. Multiple heterogeneous nuclear ribonucleoproteins (HNRNP) including HNRNPC, HNRNPG, HNRNPA2B1, are known to regulate recognize and preferentially bind $\mathrm{m}^{6} \mathrm{~A}$-containing $\mathrm{ncRNAs}$ in the nucleus $[35,59]$. It has been become clear that $\mathrm{m}^{6} \mathrm{~A}$ readers promote translation or alter mRNA stability depending on specific cellular contexts such as heat shock, viral infection, or other stresses $[35,59]$.

Multiple studies have shown crosstalk or competition between proteins that read $\mathrm{m}^{6} \mathrm{~A}$ marks [139]. Reader proteins may also localize to specific subcellular compartments by interacting with other RNAs or RNA binding proteins. Several reader proteins YTHDF1- 
3, FMR1, HNRNPA2B1 were found in the cores of mammalian stress granules while IGF2BP2-3 and HNRNPK were enriched in the protrusions of breast cancer cells [140]. Taken together, $\mathrm{m}^{6} \mathrm{~A}$ reader proteins comprise a network of physical and/or functional interactions that regulate the translation efficiency and stability of $m^{6} \mathrm{~A}$-bearing mRNAs in a context-dependent manner.

\section{$3.3 \mathrm{~m}^{6} \mathrm{~A}$ erasers}

Internal $\mathrm{m}^{6} \mathrm{~A}$ can be removed by one of two known demethylases FTO (fat-mass and obesity-associated protein) and AlkB homolog $\underline{5}$ (ALKBH5) [35, 59, 141, 142]. The demethylase activity of both FTO and ALKBH5 serves to erase $\mathrm{m}^{6} \mathrm{~A}$ marks on RNAs [35, $59,141,142]$. Similar to the readers, most erasers also work in a context-dependent manner. FTO was the first enzyme shown to remove the methyl groups from $m^{6} A$ in mRNA both in vitro and in vivo [35, 59, 141]. In addition, using cross-linking immunoprecipitation followed by high-throughput sequencing (CLIP-Seq), FTO has been demonstrated to demethylate $\mathrm{CA}-\mathrm{m}^{6} \mathrm{Am}[75,143]$. FTO was established as an $\mathrm{m}^{6} \mathrm{~A}$ demethylase by a combination of cell culture-based assays that noted small changes in overall $\mathrm{m}^{6} \mathrm{~A}$ levels and experiments that showed purified and/or recombinant FTO could de-methylate $\mathrm{m}^{6} \mathrm{~A}$ RNA in vitro [141, 144]. FTO CLIP-Seq data from multiple cell lines also revealed GAC- and/or GGAC-containing sequence motifs are significantly enriched in FTO-binding sites [145].

Recently, the consensus that FTO is a dynamic $\mathrm{m}^{6} \mathrm{~A}$ demethylase has come under increased scrutiny $[146,147]$. Me-RIP-Seq using material from $\mathrm{FTO}^{-/-}$mice showed that although a subset of $\mathrm{m}^{6} \mathrm{~A}$-containing mRNAs showed changes, the global $\mathrm{m}^{6} \mathrm{~A}$ levels were essentially unchanged in these mice [148]. Subsequent work supported this finding as $\mathrm{m}^{6} \mathrm{~A}$ consensus sequences were under-represented in mRNAs that were purified with CLIP experiments targeting FTO [149]. Together those data contradict the idea of FTO as an important $\mathrm{m}^{6} \mathrm{~A}$ demethylase $[148,149]$. FTO's role as an $\mathrm{m}^{6} \mathrm{~A}$ demethylase was further called into question when MATZER-seq studies showed little change in global $\mathrm{m}^{6} \mathrm{~A}$ in response to FTO depletion or overexpression [56]. Finally, in vitro assays showed that FTO strongly preferred $\mathrm{m}^{6} \mathrm{Am}$ (and CA-m $\mathrm{Am}$ in particular) as a substrate rather than $\mathrm{m}^{6} \mathrm{~A}$ 
[75]. Collectively, these findings challenge the established model where FTO is an $\mathrm{m}^{6} \mathrm{~A}$ demethylase in vivo [56, 75, 146-149].

While it remains an open question, a substantial body of evidence does support a role for FTO as an $\mathrm{m}^{6} \mathrm{~A}$ demethylase. For example, FTO may demethylate RNA in a compartment-specific manner where it predominantly targets $m^{6} \mathrm{~A}$ in the nucleus and $m^{6} \mathrm{Am}$ in the cytoplasm [143]. This interpretation is reasonable as FTO is predominantly a nuclear protein, although it does localize both to the nucleus and the cytoplasm in certain cell lines [141, 150]. The conflict could possibly be explained, at least in part, by the compartmentalization of FTO activity. For example, the demethylation of internal $\mathrm{m}^{6} \mathrm{~A}$ $m R N A$ and $C A-m^{6} A m$ takes place in the cytoplasm while majority of $m^{6} A$ removal happens in the nucleus [143]. A crystal structure of human FTO with a $6 \mathrm{~mA}$-modified single-stranded DNA bound in its active site provided additional mechanistic insights regarding FTO activity [151]. Further modeling of the FTO crystal structure coupled to directed point mutations showed the mechanism by which FTO could demethylate both $m^{6} A$ and $m^{6} A m[151]$. They also demonstrated that both the sequence and secondary structure contexts of the $\mathrm{m}^{6} \mathrm{~A}$ modification are key determinants of FTO activity [151].

Another possible resolution to this controversy is that FTO works in concert with other proteins to mediate its $\mathrm{m}^{6} \mathrm{~A}$ demethylase activity [152]. Using cross-linking IP coupled to mass spectrometry FTO was shown to interact with over a dozen proteins including six known RNA binding proteins including $\underline{\text { Splicing Factor Proline and Glutamine }}$ Rich (SFPQ) [152]. Notably, RNA is hypomethylated in the vicinity of SFPQ binding sites and FTO to RNA interactions were greatly enriched near SFPQ binding sites [152]. The idea that FTO could be recruited near internal $\mathrm{m}^{6} \mathrm{~A}$ sites by an RNA binding protein could explain how FTO could still recognize and demethylate $\mathrm{m}^{6} \mathrm{~A}$ despite the enzyme's $\sim 10$ fold preference for CA-m ${ }^{6} \mathrm{Am}[75,146,152]$.

\subsection{The effects of $\mathrm{m}^{6} \mathrm{~A}$ on mRNA}

Numerous studies showed that mammalian $\mathrm{m}^{6} \mathrm{~A}$ modifications are highly regulated and has profound effects on the cellular heat-shock response, stem cell proliferation and differentiation, the DNA damage response, and tumorigenesis [11, 24, 87, 117, 120, 143, 153-155]. The first evidence of $\mathrm{m}^{6} \mathrm{~A}$ causing $\mathrm{mRNA}$ instability was obtained using 
radioisotope metabolic labelling [29]. By comparing the half-lives of two populations of mRNAs (with and without $m^{6} A$ ) $m^{6} A$ inclusion was demonstrated to prominently decrease mRNA half-lives in HeLa cells [29]. In addition, depletion of METTL3, $\mathrm{m}^{6} \mathrm{~A}$ writer, resulted in the increase of mRNA stability of $\mathrm{m}^{6} \mathrm{~A}$-modified mRNAs in the cytoplasm [156]. Multiple studies have shown that $\mathrm{m}^{6} \mathrm{~A}$ does not alternate the steady-state level of cytoplasmic mRNAs, however, it serves as an imprint to mark the short half-life transcripts when they reach the cytoplasm $[117,118,157]$.

$m^{6} A$ facilitates translation via different mechanisms. $m^{6} A$ was reported to modulate mRNA translation efficiency through interactions between an $m^{6} A$ reader, YTHDF1, and eukaryotic translation initiation factor $\underline{3}$ (elF3) which then recruits the small

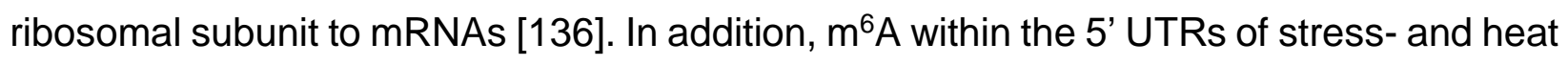
shock protein-coding mRNAs can directly bind to elF3, bypassing the normal requirement of eukaryotic translation initiation factor $\underline{4 E}$ (elF4E) and potentially enhance their translation during stress [158]. The third mechanism involves the interaction between METTL3, elF3, and mRNA cap-associated proteins present in the cytosol. These interactions may allow ribosomes paused at stop codons to reload onto the 5' UTR of transcripts while mRNAs are being translated [120].

When $\mathrm{m}^{6} \mathrm{~A}$ demethylases such as FTO and Alkbh5 were identified, the precise modification sites of $\mathrm{m}^{6} \mathrm{~A}$ as well as their biological functions were broadly revealed [89, $151,152,159]$. the view of the $\mathrm{m}^{6} \mathrm{~A}$ epitranscriptomic landscape has become comprehensible, and conclusively shows that $\mathrm{m}^{6} \mathrm{~A}$ is mainly distributed in the coding and 3 ' untranslated regions with a significant enrichment just upstream of the stop codon [38, $48,51,55,118,160]$.Therefore, the continued development of new, more sensitive technologies that can more precisely label, detect, and/or positionally pinpoint $\mathrm{m}^{6} \mathrm{~A} / \mathrm{m}$ modifications are continuously in high demand. [47, 161-165].

\section{Cap-adjacent $\mathbf{m}^{6} \mathrm{Am}$.}

Unlike $\mathrm{m}^{6} \mathrm{~A}$ which is generally situated within the body of mRNAs, CA-m ${ }^{6} \mathrm{Am}$ (Figure 4.1) occurs at the first transcribed nucleotide of the mRNA [47, 51, 74-76, 161165]. The first attempts to identify the writer of $C A-m^{6} A m$ took place shortly after the 
modification was discovered. The enzymatic activity responsible for adding a methyl group to the N6 position of cap-adjacent 2'-O-methyladenosine $(\mathrm{Am})$ to create the CA$\mathrm{m}^{6} \mathrm{Am}$ modification was isolated from fractionated HeLa cell extracts in the late 1970's

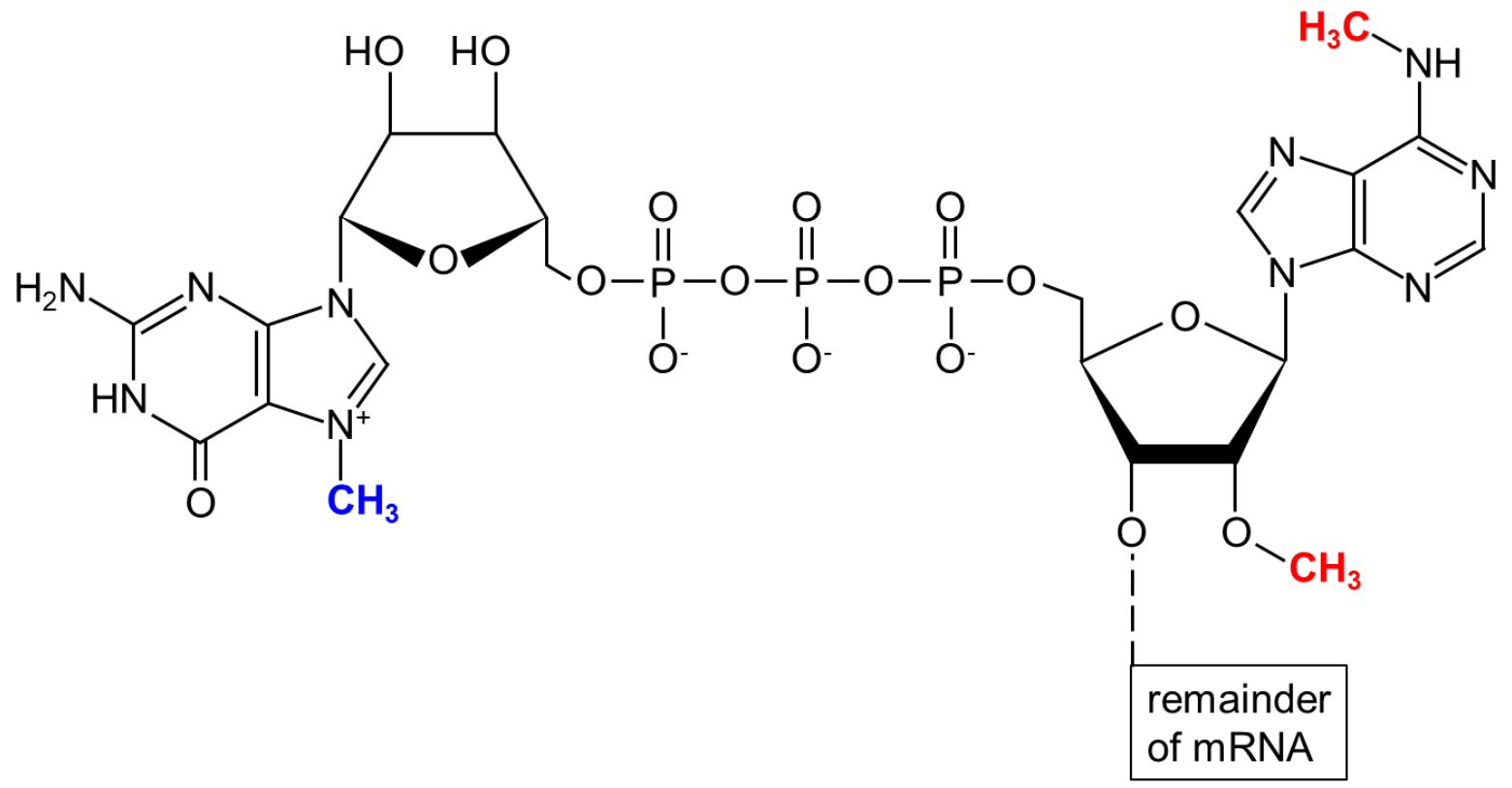

[74]. Their work further showed that the enzymatic activity was specific for $m^{7} G$ capadjacent adenosines and did not methylate adenosines within the body of the mRNA [74]. Despite their thorough work, the constraints imposed by the methods available at the time prevented them from cloning and identifying the protein(s) responsible [74]. The identity of the CA-m ${ }^{6} \mathrm{Am}$ methyltransferase would only elucidated about four decades later.

Figure 4.1: Diagram showing the chemical structures of cap-adjacent $\mathrm{m}^{6} \mathrm{Am}$, and $\mathbf{m}^{6} \mathbf{A m}$. Key methylation events within the cap and the first transcribed nucleotide are highlighted in blue and red respectively.

\subsection{PCIF1, the writer of cap-adjacent $\mathrm{m}^{6} \mathrm{Am}$}

In contrast to $\mathrm{m}^{6} \mathrm{~A}$, which is added by a complex of proteins, CA-m ${ }^{6} \mathrm{Am}$ is added to

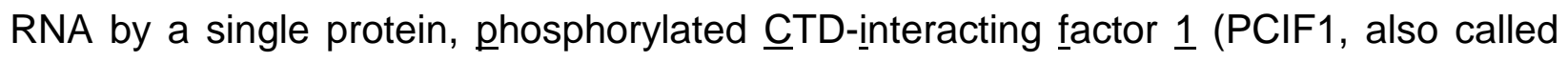
CAPAM for cap-specific adenosine methyltransferase) [47, 161-166]. For continuity, we'll refer to this protein as PCIF1 hereafter (see Box 1 for an important note concerning another protein named PCIF1). Several independent groups published studies identifying PCIF1 as the enzyme responsible for $\mathrm{CA}-\mathrm{m}^{6} \mathrm{Am}$ addition in quick succession [47, 161 163]. Each group took a slightly different track to identify the writer of $m^{6} A m$. The fractions containing CA-m ${ }^{6} \mathrm{Am}$-adding enzymatic activity were isolated from HEK293 cell 
extracts following the same workflow devised four decades earlier [74, 163]. Next, mass spectrometry was used to identify candidate proteins that co-fractionated with the CA$\mathrm{m}^{6} \mathrm{Am}$-adding activity [159]. Among the proteins in their list, they focused on PCIF1 since its evolutionary conservation suggested that it possessed methyltransferase activity [163, 167]. They validates their result when they observed a decrease in CA- $\mathrm{m}^{6} \mathrm{Am}$ when LCMS/MS was performed on mRNA harvested from cells where PCIF1 was knocked down with small interfering RNAs (siRNAs) [163]. They cross-validated this observation by demonstrating that recombinant PCIF1 could methylate a target RNA in vitro while active site point mutants could not [163]. Finally, $\mathrm{m}^{6} \mathrm{~A}$-seq studies in PCIF1 knockdown and control cells and observed a loss of signal only in the 5' UTR of mRNAs [163].

\section{Box 4.1: Two humans proteins are currently named PCIF1}

A distinct arc of papers follows a different PCIF1 protein. Those papers also refer to PDX1 C-terminal inhibiting factor 1, the human homolog of SPOP (speckle-type POZ protein) as PCIF1 [168-173]. Unfortunately, the two different proteins appear to have been named PCIF1 in quick succession (PCIF1, phosphorylated CTD interacting factor 1) in 2003 and SPOP/PCIF1 in 2004 [172, 174]. Our research shows that SPOP/PCIF1 (HGNC: 11254, Entrez Gene: 8405, Ensembl: ENSG00000121067) and PCIF1 (HGNC: 16200, Entrez Gene: 63935, Ensembl: ENSG00000100982) are in fact distinct genes with distinct protein products observed as $374(\sim 42 \mathrm{kDa})$ and $704(\sim 80 \mathrm{kDa})$ amino acids respectively. Indeed, western blots from these works show a $\sim 45 \mathrm{kDa}$ band for epitope-tagged SPOP/PCIF that matches expectations for SPOP rather than PCIF1 [171, 172]. Further the papers mentioned above show that the untagged, recombinant PCIF1 that can generate CA-m ${ }^{6} \mathrm{Am}$ is $\sim 80 \mathrm{kDa}[47]$.

CRISPR-mediated deletions of PCIF1 in cultured cells coupled to rescue experiments with exogenous functional or mutated PCIF and independently confirmed PCIF1 as the methylase required to add CA-m ${ }^{6} \mathrm{Am}$ marks $[47,161,162]$. Although the underlying approaches were consistent, each of these studies asked slightly different questions. First, RNA mass spectrometry was used to precisely compute $\mathrm{m}^{6} \mathrm{Am}$ methylation sites in the 5'-terminal cap structures of the capped mRNAs in normal and PCIF1-deleted cells [161]. Importantly, they also solved a high resolution structure that delineated the mechanism by which PCIF1 uses S-adenosylmethionine to catalyze the N6-methylation of cap-adjacent-Am to form CA-m6 Am [161]. mi-CLIP experiments in WT 
and PCIF1 knockout cells complimented experiments which observed that PCIF1 overexpression increased the prevalence of $\mathrm{CA}-\mathrm{m}^{6} \mathrm{Am}$ in cultured cells [162]. Finally, a new method called $\mathrm{m}^{6} \mathrm{Am}$-Exo-Seq, which relies on exonucleolytic digestion of uncapped RNAs, mapped the transcriptome-wide distribution $\mathrm{m}^{6} \mathrm{Am}$ vs. $\mathrm{m}^{6} \mathrm{~A}$ [47]. Their data confirmed earlier reports by showing that the signals from $\mathrm{m}^{6} \mathrm{~A}$ and $\mathrm{m}^{6} \mathrm{Am}$ sites didn't overlap, suggesting that $\mathrm{m}^{6} \mathrm{Am}$ has a function distinct from $\mathrm{m}^{6} \mathrm{~A}$ [47]. Collectively all four groups showed that PCIF1 is required for mRNA $m^{6} A m$ methylation in vivo and that recombinant PCIF1 can methylate capped mRNA in vitro [47, 161-163]. Together, these data show that PCIF1 is both necessary and sufficient to add CA-m ${ }^{6} \mathrm{Am}$ to mRNAs [47, 161-163]. The final proof was provided by Pandey et al. when, perhaps surprisingly, they succeeded in generating PCIF1-/ mice [164]. Their work confirmed PCIF1 as the sole

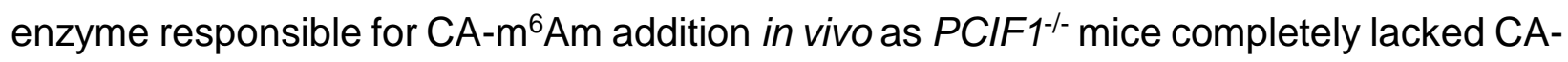
$m^{6} \mathrm{Am}[164]$.

\subsection{FTO, an $\mathrm{m}^{6} \mathrm{Am}$ eraser}

While there's some controversy as to whether FTO de-methylates $\mathrm{m}^{6} \mathrm{Am}, \mathrm{m}^{6} \mathrm{~A}$, or both in vivo, there is broad agreement that FTO de-methylates $m^{6} \mathrm{Am}$ and CA-m ${ }^{6} \mathrm{Am}$ in different types of RNA [35, 59, 75, 89, 143, 151, 152, 175]. By combining different methods FTO was convincingly shown to remove methyl groups from $\mathrm{m}^{6} \mathrm{Am}$ in different contexts. As described above, the structural basis for FTO's recognition of CA-m ${ }^{6} \mathrm{Am}$ has been established [151]. Subsequent in vitro assays showed that FTO has a much higher affinity for $m^{6} A m$, particularly $C A-m^{6} A m$, as opposed to $m^{6} A$ [75]. In fact, when recombinant FTO was added to an equimolar mixture of $\mathrm{m}^{6} \mathrm{~A}$ - and $\mathrm{m}^{6} \mathrm{Am}$-containing RNA oligonucleotides, only $\mathrm{m}^{6} \mathrm{Am}$ was demethylated [75]. Others have posited that the subcellular localization of FTO could play a role in regulating its activity [143]. That reasoning is supported by work which showed that FTO could demethylate both internal $\mathrm{m}^{6} \mathrm{Am}$ and CA-m ${ }^{6} A m$ from snRNAs and CA- ${ }^{6} A m$ from mRNAs [143]. Supporting this finding, FTO was independently demonstrated to reversibly demethylate CA-m ${ }^{6} A m$ snRNAs [89]. Deletion of FTO in adult neurons resulted in $\mathrm{m}^{6} \mathrm{Am}$-focused epitranscriptomic changes [153]. Their final observation was that deletion of FTO identified 1801 putative $\mathrm{m}^{6} \mathrm{Am}$ peaks which were enriched in developmental and DNA-RNA related genes by gene ontology [153]. 


\subsection{Functions of CA-m ${ }^{6} \mathrm{Am}$}

All investigators in the field agree that the identity and methylation status of the cap-adjacent nucleotide influences the mRNA's characteristics and several experimental systems have been established to help elucidate the function(s) of CA-m6 Am [47, 75, 161-165]. This consensus was built upon data from targeted and transcriptome-wide mapping techniques. First, overexpression of FTO alters the ratio of $\mathrm{m}^{6} \mathrm{Am}$ to $\mathrm{Am}$ in cells [75]. Next, once PCIF1 was identified as the writer of CA- $\mathrm{m}^{6} \mathrm{Am}$, wild type and Pcif1knockout cells made it possible to separate internal $\mathrm{m}^{6} \mathrm{~A}$ and $\mathrm{CA}-\mathrm{m}^{6} \mathrm{Am}$ marks on their respective mRNAs $[51,75,162]$. Overexpression of PCIF1 in HEK293T cells led to a $~ 3-$ fold increase in the $\mathrm{m}^{6} \mathrm{Am}$ to Am ratio showing that overexpression studies could also help determine the in vivo functions of $\mathrm{CA}-\mathrm{m}^{6} \mathrm{Am}$ [162]. Finally, altering the levels of CA$m^{6} \mathrm{Am}$ has effects on mRNA metabolism in vivo [47, 153, 161-164, 175]. For example, PCIF1- mice are viable but show a pronounced growth defect [164]. Further, stress and glucocorticoid exposure can change $\mathrm{m}^{6} \mathrm{Am}$ and $\mathrm{m}^{6} \mathrm{~A}$ marks and their regulatory network in a gene specific manner [153]. FTO's demethylase activity has also been linked the repression of the stem-like phenotype in colorectal cell cancers [175].

However, despite the available tools, methods, and data focusing on $\mathrm{CA}-\mathrm{m}^{6} \mathrm{Am}$, the current consensus regarding the function(s) of $\mathrm{CA}-\mathrm{m}^{6} \mathrm{Am}$ in vivo is that there is no consensus. As described below, the data from different but complimentary methods detail a general disagreement as to the function(s) of CA-m ${ }^{6} \mathrm{Am}$ and its effects on mRNA stability and translation in vivo $[47,75,161-165,176]$. In fact, every function attributed to CA- $\mathrm{m}^{6} \mathrm{Am}$; from the modification's effects on mRNA decapping, mRNA stability, and mRNA translation all require further examination and clarification $[47,75,161-165,176]$.

\subsubsection{The effects of CA-m ${ }^{6} A m$ on decapping}

CA- $\mathrm{m}^{6} \mathrm{Am}$ has been shown to resist the activity of a key decapping enzyme Dcp2 activity and was initially thought to promote RNA stability [75]. Importantly, those data are bolstered as the analysis of transcriptomic data from mouse tissues and showed evidence that CA-m ${ }^{6} \mathrm{Am}$-stabilized transcripts by inhibiting the action of the mRNA decapping enzyme DCP2 [164]. Despite these results CA-m ${ }^{6} A m$ had little effect on the decapping activity of Dcp2 in vitro [165]. That work showed that after 30 minutes of 
exposure to purified Dcp2, 25-mer RNAs beginning with three similar trinucleotide cap structures $m^{7} G-A-G, m^{7} G-A m-G$, and $m^{7} G-m^{6} A m-G$ all showed similar levels ( 65-75\%) of decapping [165]. Surprisingly, their data showed that, regardless of methylation status, RNAs beginning with an A ( 70\% decapped after 30 minutes) where much more susceptible to decapping than RNAs beginning with G, C, or $U$ are $\sim 25 \%, \sim 30 \%$, and $\sim 45 \%$ decapped respectively [165]. A key caveat is that these assays were performed entirely using an in vitro system with a short (25-mer) RNA and therefore do not account for cellular factors (such as cap binding proteins) or RNA secondary structures that could bind or obscure mRNA caps and would compete with Dcp2 in vivo [165].

\subsubsection{The effect of CA-m ${ }^{6} \mathrm{Am}$ on mRNA levels}

As mentioned above, CA- $\mathrm{m}^{6} \mathrm{Am}$ was shown to correlate with an increase in the stability of $C A-m^{6} A m$-bearing mRNAs [75]. mRNAs beginning with $C A-m^{6} A m$ were also somewhat resistant to microRNA-induced degradation [75]. Those data agreed with earlier work showing a similar increase in mRNAs with $\mathrm{m}^{6} \mathrm{~A}$ marks near their 5 ' ends [177]. An important note is that these earlier works were published prior to the identification of PCIF1 and therefore, their methods could not differentiate between CA-m ${ }^{6} \mathrm{Am}, \mathrm{m}^{6} \mathrm{Am}$, or $\mathrm{m}^{6} \mathrm{~A}$ [177]. Next, in vivo labeling experiments showed that preventing the addition of $\mathrm{CA}$ $\mathrm{m}^{6} \mathrm{Am}$ by knocking out PCIF1 significantly reduced stability of a subset of $\mathrm{m}^{6} \mathrm{Am}$ annotated mRNAs in HEK293 and HeLa cells [162]. In particular, two classes of CA$m^{6} \mathrm{Am}$-containing transcripts existed [162]. A small group of transcripts with both high very copy number and very long (24+ hours) half-lives were not affected strongly by PCIF1 knockout [162]. The second class consisted of less abundant transcripts that were particularly destabilized by the loss of $\mathrm{CA}-\mathrm{m}^{6} \mathrm{Am}$ [162]. This transcript-specific difference in mRNA stability suggest that other factors work in concert with $C A-m^{6} A m$ to influence mRNA stability.

CA-m ${ }^{6} \mathrm{Am}$ differentially regulates transcript levels in Pcif1- mouse tissues, with starkly different numbers of changed mRNAs in testes $(\sim 12,000)$, brain $(\sim 1,500)$, and spleen ( 750) [164]. Pcif1- mouse tissues also revealed the dysregulation of many pseudogenes and predicted gene transcripts [164]. In addition, transcripts with a TSS 
adenosine were predominantly down-regulated in transcriptome-wide measurements of RNA from Pcif1 1 mouse tissues [164]. An important caveat regarding these data is that while most down-regulated mRNAs began with adenosines, which was decidedly the case in testes; however, on balance across all tissues, the majority of up-regulated mRNAs began with adenosines as well [164]. The authors suggest that the regulation imparted by CA-m ${ }^{6} \mathrm{Am}$ depends upon other, likely tissue-specific, factors which confer a multi-tiered and tunable regulation to their host mRNAs.

In contrast to the data showing that $C A-m^{6} A m$ stabilizes mRNAs, others have shown that $C A-m^{6} A m$ has either the opposite effect or no effect on mRNA stability. Steady-state measurements of RNA levels showed that only 60 mRNAs changed substantially upon knockout of PCIF1 suggesting that the presence of CA-m ${ }^{6} \mathrm{Am}$ had little bearing on mRNA stability [161]. m6Am-Exo-Seq was developed to accurately map CA$m^{6} A m$, and were able to identify a subset of $C A-m^{6} A m$-bearing transcripts [47]. The combination of $\mathrm{m}^{6} \mathrm{Am}$-Exo-Seq studies and sample-matched PRO-Seq experiments showed that $m^{6} A m$ does not alter mRNA stability [158]. Rather, the changes in steadystate levels of $C A-m^{6} A m$-bearing mRNAs were fully accounted for by changes to their basal transcription rates [47]. While the effects of CA- $m^{6} A m$ on mRNAs remains debated, to date, this study offers the most complete answer as it was the only one to control for mRNA levels by assaying the transcription rates of the changed genes [47].

\subsubsection{The translation of CA-m ${ }^{6} \mathrm{Am}$-bearing mRNAs}

Recent works used a combination of reporter assays, ribosome profiling, and mass spectrometry to assess the effects of CA-m ${ }^{6} \mathrm{Am}$ on translation $[47,75,161,162,164$, 165]. As with cap binding and mRNA stability above, their data have failed to produce a consensus as to the effect(s) of $\mathrm{CA}-\mathrm{m}^{6} \mathrm{Am}$ on translation. First, ribosome profiling data taken from HEK293T cells showed that mRNAs with CA-m ${ }^{6} \mathrm{Am}$ were translated more efficiently than other mRNAs [75]. Once PCIF1's activity was identified, additional ribosome profiling data from WT and PCIF1 knockout HEK293T cells showed that the translation efficiency of $\mathrm{CA}-\mathrm{m}^{6} \mathrm{Am}$-bearing mRNAs decreased in cells where PCIF1 was 
deleted [161]. Further, their data showed that the translation of upstream open reading frames and the distribution of ribosomes were not affected by deleting PCIF1 [161].

The influence of $\mathrm{CA}-\mathrm{m}^{6} \mathrm{Am}$ on translation was further tested by transfecting meticulously purified in vitro-transcribed luciferase mRNAs into three different cell lines [165]. They reported that $m R N A$ s with $C A-m^{6} A m$ mRNAs were translated more efficiently in different cell lines that mRNAs with other beginning nucleotides [165]. The experiment centered on transfecting identical mRNAs that differed only in the identity and methylation status of the first transcribed nucleotide [165]. All their readings were normalized against luciferase mRNA possessing an adenosine in a Cap 0 context, a curious choice, since such a cap structure represents a small minority of natively-transcribed mRNAs in mammalian cells [165]. Particularly strong increases ( 7 fold $)$ in the translation of CA$\mathrm{m}^{6} \mathrm{Am}$-containing mRNA (measured by relative luciferase signals) were observed in JAWS II (immortalized immature mouse dendritic) cells with a smaller increase ( 1.5 fold) in HeLa cells and no change in 3T3-L1 cells [165]. As shown above, their data show large differences between cell types. For example, CA- $\mathrm{m}^{6} \mathrm{Am}$-bearing mRNAs were translated at a $\sim 4$ fold higher rate when comparing to the same mRNA with a Cap 1 guanosine in 3T3-L1 and HeLa cells but they report a $\sim 60$ fold range for the same comparison in JAWS II cells [165]. This difference is startling as the transfected mRNAs differ only by their first nucleotide and could evince an unknown translational control mechanism in JAWS II cells.

The analysis of ribosome profiling data from Pcif1\% mouse brain tissue showed either up- or down regulation of translation depending upon the mRNA [164]. A comparatively small number of mRNAs exhibited increased or decreased translational efficiency with similar numbers of mRNAs showing increased or decreased translation [164]. However, they found no correlation between changes in translation rates and the first transcribed nucleotide of the affected mRNA, suggesting that the observed change in translation was independent of $\mathrm{CA}-\mathrm{m}^{6} \mathrm{Am}$ [164]. Another ribosome profiling study also showed that the translation rates and protein levels of high confidence CA-m ${ }^{6}$ Am mRNAs were essentially unchanged in PCIF1 knockout HEK293T cells [162]. 
Contradicting those results, several methods showed that $C A-m^{6} A m$ marks negatively influenced the translation of their mRNAs [47]. In a similar experiment to the one described above, purified in vitro-transcribed EGFP mRNAs beginning with either $\mathrm{m}^{7} \mathrm{G}$-cap-m ${ }^{6} \mathrm{Am}$ or $\mathrm{m}^{7} \mathrm{G}$-cap-Am were transfected into WT and PCIF1-deleted MEL624 cells. The coupling of fluorescence microscopy with flow cytometry showed that CA$\mathrm{m}^{6} \mathrm{Am}$-bearing mRNAs produced quantitatively lower GFP signals [47]. Next, by adding an in vitro-transcribed dual luciferase reporter RNA to a common rabbit reticulocyte lysate translation system $\mathrm{CA}-\mathrm{m}^{6} \mathrm{Am}$ was shown to decrease the translation of the reporter in a cap-dependent manner [47]. Finally, mass spectrometry experiments comparing WT and PCIF1 knockout MEL624 cells showed that the levels of over 500 proteins increased, compared to 17 decreases, when PCIF1 was deleted [47]. Taken together, their data show that CA-m ${ }^{6} \mathrm{Am}$ negatively impacts cap-dependent translation of methylated mRNAs in MEL624 cell line [47].

In summary, as with the effect of CA- $\mathrm{m}^{6} \mathrm{Am}$ on decapping and mRNA stability, the data regarding this epitranscriptomic mark's role in translation are contradictory and require further investigation and clarification.

\section{Table 2: Salient questions regarding cap-adjacent $\mathrm{m}^{6} \mathrm{Am}$}

\begin{tabular}{|c|c|}
\hline Unanswered Question & Reasoning / Implication \\
\hline What is/are the role(s) of CA-m ${ }^{6} \mathrm{Am}$ in vivo? & $\begin{array}{l}\text { This fundamental question is still up for debate as } \\
\text { several studies have yielded conflicting data. }\end{array}$ \\
\hline $\begin{array}{l}\text { Precisely how much of } \mathrm{m}^{6} \mathrm{~A} \text { signal is } \\
\text { actually CA-m }{ }^{6} \mathrm{Am} \text { ? }\end{array}$ & $\begin{array}{l}\text { The current assumption is that } \sim 100 \% \text { of the } \mathrm{m}^{6} \mathrm{~A} \\
\text { signal mapping to TSS and across the } 5 \text { ' UTR is } \\
\text { actually CA- } \mathrm{m}^{6} \mathrm{Am} \text {. Is this true? }\end{array}$ \\
\hline What is the role of CA-m $\mathrm{m}^{6} \mathrm{Am}$ in stress? & $\begin{array}{l}\text { Loss of PCIF1 has been shown to sensitize cells to } \\
\text { oxidative stress. What mechanism surveys CA-m }{ }^{6} \mathrm{Am} \\
\text { in stress? Does it apply to other stressors? }\end{array}$ \\
\hline $\begin{array}{l}\text { Which other decapping enzymes also have } \\
\text { difficulty with removing CA-m }{ }^{6} \mathrm{Am} \text { ? } \\
\text { Do any decapping enzymes preferentially } \\
\text { decap RNAs with CA-m }{ }^{6} \mathrm{Am} \text { ? }\end{array}$ & $\begin{array}{l}\text { Many decapping enzymes are known in eukaryotes, } \\
\text { most of which are poorly-characterized. Could one or } \\
\text { more of these enzymes serve as CA-m }{ }^{6} \text { Am readers? }\end{array}$ \\
\hline $\begin{array}{l}\text { Are all other cap binding proteins also CA- } \\
\mathrm{m}^{6} \mathrm{Am} \text { readers? }\end{array}$ & \multirow{2}{*}{$\begin{array}{l}\text { The affinity of both eIF4E and Dcp } 2 \text { for capped } \\
\text { mRNAs are affected by the presence of CA-m }{ }^{6} \mathrm{Am} \text {. Do } \\
\text { additional proteins (cap-binding or other) serve as CA- } \\
\mathrm{m}^{6} \mathrm{Am} \text { readers? }\end{array}$} \\
\hline $\begin{array}{l}\text { What other cellular factors function as CA- } \\
\mathrm{m}^{6} \mathrm{Am} \text { readers? }\end{array}$ & \\
\hline Is FTO the only CA-m ${ }^{6} \mathrm{Am}$ demethylase? & $\begin{array}{l}\mathrm{m}^{6} \mathrm{~A} \text { appears to have two functional demethylases. } \\
\text { Could the same be true for CA- } \mathrm{m}^{6} \mathrm{Am} \text { ? }\end{array}$ \\
\hline
\end{tabular}




\begin{tabular}{|l|l|}
\hline $\begin{array}{l}\text { Does a particular FTO-interacting protein } \\
\text { target it to CA-m }{ }^{6} \mathrm{Am} ?\end{array}$ & $\begin{array}{l}\text { Interactions with another protein could offer a broader } \\
\text { regulatory potential by fine-tuning FTO's CA-m }{ }^{6} \mathrm{Am} \\
\text { demethylase activity. }\end{array}$ \\
\hline $\begin{array}{l}\text { Is there an interplay between CA-m }{ }^{6} \mathrm{Am} \text { and } \\
\text { other RNA modifications or the proteins that } \\
\text { recognize them? }\end{array}$ & $\begin{array}{l}\text { Interactions between proteins that recognize CA- } \\
\text { m6Am and other epitranscriptomic marks would } \\
\text { expand their regulatory potential. }\end{array}$ \\
\hline $\begin{array}{l}\text { Can cap-adjacent Am be methylated to form } \\
\text { CA-m }{ }^{6} \mathrm{Am} \text { in the cytoplasm? }\end{array}$ & $\begin{array}{l}\text { Since most mature mRNAs are localized to the } \\
\text { cytoplasm, cytoplasmic addition CA-m }{ }^{6} \text { Am would } \\
\text { offer more dynamic regulation of the targeted mRNAs. }\end{array}$ \\
\hline
\end{tabular}

\section{Unanswered questions regarding cap-adjacent $\mathrm{m}^{6} \mathrm{Am}$}

As described in detail above, many questions regarding the biological function(s) of CA-m ${ }^{6} \mathrm{Am}$ lack definitive answers. Currently, it is thought that yet to be identified celltype specific factors are the likeliest drivers of these divergent results [176]. As with the controversy regarding FTO as an eraser of $\mathrm{m}^{6} \mathrm{~A}$ marks in vivo, the hope is that newer, more sensitive methods will help resolve the apparent conflicts with the reported data [ ]. The identification of PCIF1 as the writer of CA-m ${ }^{6} \mathrm{Am}$ and the availability of PCIF $1 \%$ cells and mice have opened the door to asking many new questions (Table 2) regarding the role of $\mathrm{CA}-\mathrm{m}^{6} \mathrm{Am}$ in vivo. We discuss two of these unanswered questions in greater detail.

\subsection{Is CA-m ${ }^{6} \mathrm{Am}$ addition by PCIF1 truly a co-transcriptional event?}

The presence of PCIF1's WW domain and the papers showing interactions with the phosphorylate C-terminal of RNA polymerase II, it's been assumed that CA-m ${ }^{6} \mathrm{Am}$ addition is co-transcriptional [161, 174, 178]. Supporting this idea, exogenouslyexpressed, epitope-tagged PCIF does localize predominantly to the nucleus, although cytoplasmic staining is visible for some cells, particularly for inactive point mutations of PCIF1 [47]. Indirect immunofluorescence shows that PCIF1 is predominantly nuclear in most mouse tissues, although as with other works some degree of cytoplasmic staining is evident in some of the images presented [47, 164]. A careful reading of the older literature revealed that the $\mathrm{CA}-\mathrm{m}^{6} \mathrm{Am}$ adding activity had been isolated from the cytoplasm of HeLa cells [74]. By coupling differential centrifugation to multiple rounds of column chromatography $\mathrm{CA}-\mathrm{m}^{6} \mathrm{Am}$ addition was performed by a cytoplasmic enzyme which was not associated with ribosomes, the mitochondria, or nuclei [74]. Confirming that result, the first demonstration of PCIF1 as the CA-m ${ }^{6} \mathrm{Am}$ methyltransferase used 
cytoplasmic extracts from HEK293 cells to isolate the activity [sun]. Re-examination of the other recent studies revealed that all experiments measuring $C A-m^{6} A m$ deposition and PCIF1 activity were performed with whole cell lysates or extracts or with tagged constructs rather than the endogenous proteins $[47,75,161,162,164]$. Demonstrating that PCIF1 co-immunoprecipitates the phosphorylated C-terminal domain of RNA polymerase II offers the most direct proof that PCIF1 works co-transcriptionally [161]. However, those data were obtained using whole cell extracts, opening the possibility that the interaction with the C-terminal domain of RNA polymerase II could be an artifact caused by the destruction of the nuclear membrane during cell lysis [161]. By showing that PCIF1 is predominantly localized in the cytoplasm of HUVECs (Figure 5.1) our data are consistent with a cytoplasmic role for PCIF1.

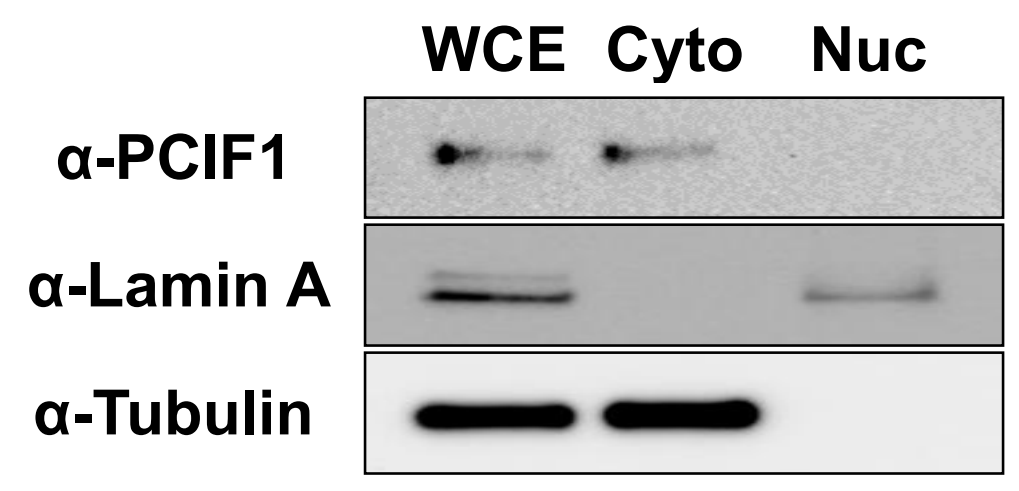

Figure 5.1: Western blots demonstrate that PCIF1 is cytoplasmic in HUVEC cells. HUVEC cells were cultured in Vascular Cell Basal Medium (ATCC PCS-100-030) supplemented with Endothelial Cell Growth Kit-VEGF (ATCC PCS-100-041) at $37^{\circ} \mathrm{C}$ and $5 \% \mathrm{CO}_{2}$. $\sim 80 \%$ confluent cultures were rinsed with PBS and harvested using a cell lifter. Cell pellets were resuspended in $0.9 \mathrm{ml}$ of lysis buffer (PBS pH7.4, 0.1\% NP40 (Thermofisher), 0.1M PMSF (Sigma), protease inhibitor cocktail (Sigma), and phosphatase inhibitor (Sigma)) for $10 \mathrm{~min} .300 \mu \mathrm{l}$ cell lysate was collected as whole cell extract (WCE) and sonicated for an hour at $4 \mathrm{C}$ using a Bioruptor Plus (Diagenode). The remaining cell lysate $(600 \mu \mathrm{l})$ was then centrifuged for $1 \mathrm{~min}$ at $21,000 \mathrm{xG}$ and the supernatant was transferred to a new tube as cytoplasmic extracts (Cyto). The pelleted nuclei were rinsed once with lysis buffer, resuspended in fresh lysis buffer and sonicated for an hour. Equal amounts of protein were separated using Mini-PROTEAN TGX Stainfree AnyKD gels (Biorad,) and blotted onto TransBlot Turbo PVDF Membrane (Biorad). Blots were blocked using 5\% skim milk and probed with a-PCIF1 (Abcam, ab205016), $\alpha$ - Lamin A (Invitrogen, MA1-06101, nuclear marker), and $\alpha$-Tubulin (Proteintech 66031-I-Ig, cytoplasmic marker). Data presented are a single representative experiment from independent biological triplicate experiments. 


\subsection{Could PCIF1 function in concert with cytoplasmic capping?}

A cytoplasmic complex that adds a cap onto 5'-monophosphate RNAs and is capable of restoring $\mathrm{m}^{7} \mathrm{G}$ caps to mRNAs in the cytoplasm was identified in 2009 [100]. The cytoplasmic capping complex includes RNGTT, NCK Adaptor Protein 1 (NCK1), an unidentified 5'-monophosphate kinase, and a heterodimer of RNMT with its activating subunit RAMAC or RAM, [100-102]. NCK1 is a scaffold protein to coordinate the activities of RNGTT, a monophosphate kinase and the RNMT:RAMAC heterodimer interact to form the active complex in the cytoplasm [27, 101]. Importantly, the cell fractionation data provide strong supporting evidence for cytoplasmic capping as their cytoplasmic extracts also possessed a methyltransferase activity capable of converting a G-capped RNA into a proper $m^{7} G$ cap [74]. Inhibition of cytoplasmic cap methylation was used to identify 5' terminal oligopyrimidine (TOP)-containing mRNAs as cytoplasmic capping targets and uncovered cytoplasmic capping sites downstream of canonical 5' ends [179]. Although the overall biological significance of cytoplasmic capping remains poorly understood, several reports show that cytoplasmic capping targets are enriched in mRNAs involved in mitotic cell cycle control, cellular stress responses, and development [102, 180].

We have long thought that epitranscriptomic modifications may be among the keys to better understanding cytoplasmically-capped mRNAs. For this reason, we are examining whether $\mathrm{m}^{6} \mathrm{~A}$ and/or $\mathrm{m}^{6} \mathrm{Am}$ play an important role in cytoplasmically-capped mRNAs. Possibly supporting this idea, numerous internally mapped $m^{6} A m$ sites $(16.7 \%$ of total) have been identified [162]. While internally-mapping $\mathrm{m}^{6} \mathrm{Am}$ sites were interpreted as arising from alternative TSSs, such $C A-m^{6} A m$ sites could also arise from the cytoplasmic capping of truncated mRNAs [46, 162, 179-181]. By showing that PCIF1 localizes to the cytoplasm, (Figure 5.1), our cell fractionation data agree with two papers demonstrating $\mathrm{CA}-\mathrm{m}^{6} \mathrm{Am}$-adding activity in the cytoplasm [74]. Together, these data imply that PCIF1 functions in the cytoplasm, either in addition to- or instead of, the nucleus. If confirmed, the cytoplasmic addition of CA- ${ }^{6} \mathrm{Am}$ could serve as a consequential and dynamic epitranscriptomic mark that helps regulate the translation and stability of mRNAs.

\section{Closing remarks}


The field of epitranscriptomics has advanced greatly since the discovery of the first modified RNA nucleotide in 1957 [1]. While roughly 160 different RNA base modifications are currently known, most of them are poorly characterized. Furthermore, their functions, and the enzymes that write, read, and erase many RNA modifications remain unknown $[8,9]$. This void of knowledge and the contradictory nature of some of the results are both certainly contributors to some of the recent skepticism regarding a functional and dynamic epitranscriptome [147, 157]. As epitranscriptomics continues to grow rapidly, we should expect (indeed, we should welcome) seemingly contradictory findings such as the apparently opposing effect(s) of CA- $\mathrm{m}^{6} \mathrm{Am}$ on mRNA decapping, stability, and translation, the compartmentalization of PCIF1 activity, or the target(s) of the FTO demethylase [35, $47,89,161-165]$. While such conflicting results can be confusing, they provide singular opportunities to better understand the fundamental biological mechanism(s) underlying the contradiction. In general, such conflicts can be resolved as new tools, techniques, and insights enable a more complete investigation of the systems involved. The multitude of unanswered questions ensures that advances in epitranscriptomics will continue to yield impactful findings for years to come.

\section{Acknowledgements}

The authors would like to thank their colleagues in the Kiss lab and the Department of Cardiovascular Sciences at the Houston Methodist Research Institute (HMRI) for creating an innovative, challenging, yet welcoming scientific environment. TTT was supported by funds from the Cancer Prevention and Research Institute of Texas (CPRIT, grant RP150611 to J.P. Cooke, MD, PhD.). DLK was supported by start-up funds provided by the HMRI (to DLK) and grants from CPRIT (RP150611), the American Heart Association (20CDA35310329 to DLK), and the National Institutes of Health (1R35GM137819 to DLK). The content presented here is solely the responsibility of the authors and does not represent the official views of the HMRI, CPRIT, the American Heart Association or the National Institutes of Health. 


\section{REFERENCES}

1. Davis, F.F. and F.W. Allen, Ribonucleic acids from yeast which contain a fifth nucleotide. J Biol Chem, 1957. 227(2): p. 907-15.

2. Cohn, W.E., Pseudouridine, a carbon-carbon linked ribonucleoside in ribonucleic acids: isolation, structure, and chemical characteristics. J Biol Chem, 1960. 235: p. 1488-98.

3. He, C., Grand challenge commentary: RNA epigenetics? Nat Chem Biol, 2010. 6(12): p. 863-5.

4. Saletore, Y., et al., The birth of the Epitranscriptome: deciphering the function of RNA modifications. Genome Biol, 2012. 13(10): p. 175.

5. Kadumuri, R.V. and S.C. Janga, Epitranscriptomic Code and Its Alterations in Human Disease. Trends Mol Med, 2018. 24(10): p. 886-903.

6. Meyer, K.D. and S.R. Jaffrey, The dynamic epitranscriptome: N6-methyladenosine and gene expression control. Nat Rev Mol Cell Biol, 2014. 15(5): p. 313-26.

7. Roundtree, I.A., et al., Dynamic RNA Modifications in Gene Expression Regulation. Cell, 2017. 169(7): p. 1187-1200.

8. Boccaletto, P., et al., MODOMICS: a database of RNA modification pathways. 2017 update. Nucleic Acids Res, 2018. 46(D1): p. D303-D307.

9. Crain, P.F. and J.A. McCloskey, The RNA modification database. Nucleic Acids Res, 1996. 24(1): p. 98-9.

10. Meyer, K.D., et al., Comprehensive analysis of mRNA methylation reveals enrichment in 3' UTRs and near stop codons. Cell, 2012. 149(7): p. 1635-46.

11. Jonkhout, N., et al., The RNA modification landscape in human disease. RNA, 2017. 23(12): p. 1754-1769.

12. Reddy, R., et al., MOdified nucleosides of nuclear and nucleolar low molecular weight ribonucleic acid. J Biol Chem, 1972. 247(22): p. 7245-50.

13. Miura, K., et al., The 5'-terminal nucleotide sequences of the double-stranded RNA of human reovirus. Proc Natl Acad Sci U S A, 1974. 71(10): p. 3979-83.

14. Reddy, R., et al., Primary sequence of $U-1$ nuclear ribonucleic acid of Novikoff hepatoma ascites cells. J Biol Chem, 1974. 249(20): p. 6486-94.

15. Rottman, F., A.J. Shatkin, and R.P. Perry, Sequences containing methylated nucleotides at the $5^{\prime}$ termini of messenger RNAs: possible implications for processing. Cell, 1974. 3(3): p. 197-9.

16. Furuichi, Y., S. Muthukrishnan, and A.J. Shatkin, 5'-Terminal m-7G(5')ppp(5')G-m-p in vivo: identification in reovirus genome RNA. Proc Natl Acad Sci U S A, 1975. 72(2): p. 742-5.

17. Ro-Choi, T.S., et al., Nucleotide sequence of $U-2$ ribonucleic acid. The sequence of the $5^{\prime}-$ terminal oligonucleotide. J Biol Chem, 1975. 250(10): p. 3921-8.

18. Shibata, H., et al., The primary nucleotide sequence of nuclear U-2 ribonucleic acid. The 5'terminal portion of the molecule. J Biol Chem, 1975. 250(10): p. 3909-20.

19. Ensinger, M.J. and B. Moss, Modification of the 5' terminus of mRNA by an RNA (guanine7-)-methyltransferase from HeLa cells. J Biol Chem, 1976. 251(17): p. 5283-91.

20. Shatkin, A.J., Capping of eucaryotic mRNAs. Cell, 1976. 9(4 PT 2): p. 645-53. 
21. Ro-Choi, T.S. and D. Henning, Sequence of 5'-oligonucleotide of U1 RNA from Novikoff hepatoma cells. J Biol Chem, 1977. 252(11): p. 3814-20.

22. Grosjean, H., et al., Intron-dependent enzymatic formation of modified nucleosides in eukaryotic tRNAs: a review. Biochimie, 1997. 79(5): p. 293-302.

23. Janin, M., L. Coll-SanMartin, and M. Esteller, Disruption of the RNA modifications that target the ribosome translation machinery in human cancer. Mol Cancer, 2020. 19(1): p. 70.

24. Dong, Z. and H. Cui, The Emerging Roles of RNA Modifications in Glioblastoma. Cancers (Basel), 2020. 12(3).

25. Goh, Y.T., et al., METTL4 catalyzes m6Am methylation in U2 snRNA to regulate pre-mRNA splicing. Nucleic Acids Res, 2020. 48(16): p. 9250-9261.

26. Linder, B., et al., Single-nucleotide-resolution mapping of m6A and m6Am throughout the transcriptome. Nat Methods, 2015. 12(8): p. 767-72.

27. Trotman, J.B. and D.R. Schoenberg, A recap of RNA recapping. Wiley Interdiscip Rev RNA, 2018: p. e1504.

28. Schoenberg, D.R. and L.E. Maquat, Re-capping the message. Trends Biochem Sci, 2009. 34(9): p. 435-42.

29. Sommer, S., U. Lavi, and J.E. Darnell, Jr., The absolute frequency of labeled N-6methyladenosine in HeLa cell messenger RNA decreases with label time. J Mol Biol, 1978. 124(3): p. 487-99.

30. Clancy, M.J., et al., Induction of sporulation in Saccharomyces cerevisiae leads to the formation of N6-methyladenosine in mRNA: a potential mechanism for the activity of the IME4 gene. Nucleic Acids Res, 2002. 30(20): p. 4509-18.

31. Zhong, S., et al., MTA is an Arabidopsis messenger RNA adenosine methylase and interacts with a homolog of a sex-specific splicing factor. Plant Cell, 2008. 20(5): p. 1278-88.

32. Bokar, J.A., et al., Purification and CDNA cloning of the AdoMet-binding subunit of the human mRNA (N6-adenosine)-methyltransferase. RNA, 1997. 3(11): p. 1233-47.

33. Bokar, J.A., et al., Characterization and partial purification of mRNA N6-adenosine methyltransferase from HeLa cell nuclei. Internal mRNA methylation requires a multisubunit complex. J Biol Chem, 1994. 269(26): p. 17697-704.

34. Rottman, F.M., et al., N6-adenosine methylation in mRNA: substrate specificity and enzyme complexity. Biochimie, 1994. 76(12): p. 1109-14.

35. Zaccara, S., R.J. Ries, and S.R. Jaffrey, Reading, writing and erasing mRNA methylation. Nat Rev Mol Cell Biol, 2019. 20(10): p. 608-624.

36. Anreiter, I., et al., New Twists in Detecting mRNA Modification Dynamics. Trends Biotechnol, 2020.

37. Ovcharenko, A. and A. Rentmeister, Emerging approaches for detection of methylation sites in RNA. Open Biol, 2018. 8(9).

38. Linder, B. and S.R. Jaffrey, Discovering and Mapping the Modified Nucleotides That Comprise the Epitranscriptome of mRNA. Cold Spring Harb Perspect Biol, 2019. 11(6).

39. Liu, H., et al., Accurate detection of m(6)A RNA modifications in native RNA sequences. Nat Commun, 2019. 10(1): p. 4079.

40. Parker, M.T., et al., Nanopore direct RNA sequencing maps the complexity of Arabidopsis $m R N A$ processing and $m(6)$ A modification. Elife, 2020. 9. 
41. Zhao, L., et al., Analysis of Transcriptome and Epitranscriptome in Plants Using PacBio IsoSeq and Nanopore-Based Direct RNA Sequencing. Front Genet, 2019. 10: p. 253.

42. Lorenz, D.A., et al., Direct RNA sequencing enables $m(6) A$ detection in endogenous transcript isoforms at base-specific resolution. RNA, 2020. 26(1): p. 19-28.

43. Viehweger, A., et al., Direct RNA nanopore sequencing of full-length coronavirus genomes provides novel insights into structural variants and enables modification analysis. Genome Res, 2019. 29(9): p. 1545-1554.

44. Enroth, C., et al., Detection of internal N7-methylguanosine (m7G) RNA modifications by mutational profiling sequencing. Nucleic Acids Res, 2019. 47(20): p. e126.

45. Marchand, V., et al., AlkAniline-Seq: Profiling of $m(7) G$ and $m(3) C$ RNA Modifications at Single Nucleotide Resolution. Angew Chem Int Ed Engl, 2018. 57(51): p. 16785-16790.

46. Fejes-Toth K, S.V., Sachidanandam R, Assaf G, Hannon GJ, Kapranov P, Foissac S, Willingham AT, Duttagupta R, Dumais E, Gingeras TR., Post-transcriptional processing generates a diversity of 5'-modified long and short RNAs. Nature, 2009. 457(7232): p. 1028-32.

47. Sendinc, E., et al., PCIF1 Catalyzes m6Am mRNA Methylation to Regulate Gene Expression. Mol Cell, 2019. 75(3): p. 620-630 e9.

48. Koh, C.W.Q., Y.T. Goh, and W.S.S. Goh, Atlas of quantitative single-base-resolution N(6)methyl-adenine methylomes. Nat Commun, 2019. 10(1): p. 5636.

49. Dominissini, D., et al., Topology of the human and mouse m6A RNA methylomes revealed by m6A-seq. Nature, 2012. 485(7397): p. 201-6.

50. Molinie, B., et al., $m(6) A-L A I C$-seq reveals the census and complexity of the $m(6) A$ epitranscriptome. Nat Methods, 2016. 13(8): p. 692-8.

51. Hawley, B.R. and S.R. Jaffrey, Transcriptome-Wide Mapping of $m(6) A$ and $m(6) A m$ at Single-Nucleotide Resolution Using miCLIP. Curr Protoc Mol Biol, 2019. 126(1): p. e88.

52. Chen, K., et al., High-resolution N(6) -methyladenosine (m(6) A) map using photocrosslinking-assisted m(6) A sequencing. Angew Chem Int Ed Engl, 2015. 54(5): p. 158790.

53. Hsu, P.J. and C. He, High-Resolution Mapping of $N$ (6)-Methyladenosine Using m(6)A Crosslinking Immunoprecipitation Sequencing (m(6)A-CLIP-Seq). Methods Mol Biol, 2019. 1870: p. 69-79.

54. Shu, X., et al., A metabolic labeling method detects $m(6) A$ transcriptome-wide at single base resolution. Nat Chem Biol, 2020. 16(8): p. 887-895.

55. Wang, Y., et al., Antibody-free enzyme-assisted chemical approach for detection of N(6)methyladenosine. Nat Chem Biol, 2020. 16(8): p. 896-903.

56. Garcia-Campos, M.A., et al., Deciphering the "m(6)A Code" via Antibody-Independent Quantitative Profiling. Cell, 2019. 178(3): p. 731-747 e16.

57. Zhang, Z., et al., Single-base mapping of $m(6) A$ by an antibody-independent method. Sci Adv, 2019. 5(7): p. eaax0250.

58. Mongan, N.P., R.D. Emes, and N. Archer, Detection and analysis of RNA methylation. F1000Res, 2019. 8.

59. Shi, H., J. Wei, and C. He, Where, When, and How: Context-Dependent Functions of RNA Methylation Writers, Readers, and Erasers. Mol Cell, 2019. 74(4): p. 640-650. 
60. Liu, J. and G. Jia, Methylation modifications in eukaryotic messenger RNA. J Genet Genomics, 2014. 41(1): p. 21-33.

61. Schibler, U. and R.P. Perry, Characterization of the 5' termini of hn RNA in mouse L cells: implications for processing and cap formation. Cell, 1976. 9(1): p. 121-30.

62. Perry, R.P., et al., The methylated constituents of $L$ cell messenger RNA: evidence for an unusual cluster at the 5' terminus. Cell, 1975. 4(4): p. 387-94.

63. Lavi, U., R. Fernandez-Munoz, and J.E. Darnell, Jr., Content of N-6 methyl adenylic acid in heterogeneous nuclear and messenger RNA of HeLa cells. Nucleic Acids Res, 1977. 4(1): p. 63-9.

64. Schibler, U. and R.P. Perry, The 5'-termini of heterogeneous nuclear RNA: a comparison among molecules of different sizes and ages. Nucleic Acids Res, 1977. 4(12): p. 4133-49.

65. Perry, R.P. and D.E. Kelley, Methylated constituents of heterogeneous nuclear RNA: presence in blocked 5' terminal structures. Cell, 1975. 6(1): p. 13-9.

66. Wei, C., A. Gershowitz, and B. Moss, N6, O2'-dimethyladenosine a novel methylated ribonucleoside next to the 5' terminal of animal cell and virus mRNAs. Nature, 1975. 257(5523): p. 251-3.

67. Cheng, T.C. and H.H. Kazazian, Jr., The 5'-terminal structures of murine alpha- and betaglobin messenger RNA. J Biol Chem, 1977. 252(5): p. 1758-63.

68. Cho, S., T. Cheng, and H.H. Kazazian, Jr., Characterization of 5'-terminal methylation of human alpha- and beta-globin mRNAs. J Biol Chem, 1978. 253(16): p. 5558-61.

69. Crain, P.F., et al., Characterization of N6, O2-dimethyladenosine from nuclear RNA of Novikoff hepatoma. Nucleic Acids Res, 1978. 5(3): p. 771-6.

70. Dubin, D.T. and R.H. Taylor, The methylation state of poly A-containing messenger RNA from cultured hamster cells. Nucleic Acids Res, 1975. 2(10): p. 1653-68.

71. Salditt-Georgieff, M., et al., Methyl labeling of HeLa cell hnRNA: a comparison with mRNA. Cell, 1976. 7(2): p. 227-37.

72. Sommer, S., et al., The methylation of adenovirus-specific nuclear and cytoplasmic RNA. Nucleic Acids Res, 1976. 3(3): p. 749-65.

73. Ven Murthy, M.R., Blocked and methylated 5'-terminal cap structures of rat brain messenger ribonucleic acids. J Neurochem, 1982. 38(1): p. 28-40.

74. Keith, J.M., M.J. Ensinger, and B. Moss, HeLa cell RNA (2'-O-methyladenosine-N6-)methyltransferase specific for the capped 5'-end of messenger RNA. J Biol Chem, 1978. 253(14): p. 5033-9.

75. Mauer, J., et al., Reversible methylation of $m(6) A m$ in the 5' cap controls mRNA stability. Nature, 2017. 541(7637): p. 371-375.

76. Wang, J., et al., Quantifying the RNA cap epitranscriptome reveals novel caps in cellular and viral RNA. Nucleic Acids Res, 2019. 47(20): p. e130.

77. Dunn, D.B., The isolation of 5-methylcytidine from RNA. Biochim Biophys Acta, 1960. 38 : p. 176-8.

78. Smith, J.D. and D.B. Dunn, The occurrence of methylated guanines in ribonucleic acids from several sources. Biochem J, 1959. 72(2): p. 294-301.

79. Dunn, D.B., The occurrence of 1-methyladenine in ribonucleic acid. Biochim Biophys Acta, 1961. 46: p. 198-200. 
80. Lamond, A.L., The trimethyl-guanosine cap is a nuclear targeting signal for snRNPs. Trends Biochem Sci, 1990. 15(12): p. 451-2.

81. Rajecka, V., T. Skalicky, and S. Vanacova, The role of RNA adenosine demethylases in the control of gene expression. Biochim Biophys Acta Gene Regul Mech, 2019. 1862(3): p. 343355.

82. Tajaddod, M., M.F. Jantsch, and K. Licht, The dynamic epitranscriptome: A to I editing modulates genetic information. Chromosoma, 2016. 125(1): p. 51-63.

83. Dominissini, D. and G. Rechavi, Loud and Clear Epitranscriptomic m(1)A Signals: Now in Single-Base Resolution. Mol Cell, 2017. 68(5): p. 825-826.

84. Squires, J.E., et al., Widespread occurrence of 5-methylcytosine in human coding and noncoding RNA. Nucleic Acids Res, 2012. 40(11): p. 5023-33.

85. Frye, M. and F.M. Watt, The RNA methyltransferase Misu (NSun2) mediates Myc-induced proliferation and is upregulated in tumors. Curr Biol, 2006. 16(10): p. 971-81.

86. Boo, S.H. and Y.K. Kim, The emerging role of RNA modifications in the regulation of $m R N A$ stability. Exp Mol Med, 2020. 52(3): p. 400-408.

87. Engel, M. and A. Chen, The emerging role of $m R N A$ methylation in normal and pathological behavior. Genes Brain Behav, 2018. 17(3): p. e12428.

88. Hussain, S., et al., Characterizing 5-methylcytosine in the mammalian epitranscriptome. Genome Biol, 2013. 14(11): p. 215.

89. Mauer, J., et al., FTO controls reversible m(6)Am RNA methylation during snRNA biogenesis. Nat Chem Biol, 2019. 15(4): p. 340-347.

90. Furuichi, Y. and A.J. Shatkin, Viral and cellular mRNA capping: past and prospects. Adv Virus Res, 2000. 55: p. 135-84.

91. Shatkin, A.J., mRNA caps--old and newer hats. Bioessays, 1987. 7(6): p. 275-7.

92. Ghosh, A. and C.D. Lima, Enzymology of RNA cap synthesis. Wiley Interdiscip Rev RNA, 2010. 1(1): p. 152-72.

93. Ramanathan, A., G.B. Robb, and S.H. Chan, mRNA capping: biological functions and applications. Nucleic Acids Res, 2016. 44(16): p. 7511-26.

94. Pillutla, R.C., et al., Human mRNA capping enzyme (RNGTT) and cap methyltransferase (RNMT) map to 6q16 and 18p11.22-p11.23, respectively. Genomics, 1998. 54(2): p. 3513.

95. Pillutla, R.C., et al., Recombinant human mRNA cap methy/transferase binds capping enzyme/RNA polymerase Ilo complexes. J Biol Chem, 1998. 273(34): p. 21443-6.

96. Furuichi, Y., M.A. Morgan, and A.J. Shatkin, Synthesis and translation of mRNA containing 5'-terminal 7-ethylguanosine cap. J Biol Chem, 1979. 254(14): p. 6732-8.

97. Shatkin, A.J., et al., 5'-Terminal caps, cap-binding proteins and eukaryotic mRNA function. Biochem Soc Symp, 1982. 47: p. 129-43.

98. Sonenberg, N., et al., Differential stimulation of capped mRNA translation in vitro by cap binding protein. Nature, 1980. 285(5763): p. 331-3.

99. Tahara, S.M., M.A. Morgan, and A.J. Shatkin, Two forms of purified $m 7 G$-cap binding protein with different effects on capped mRNA translation in extracts of uninfected and poliovirus-infected HeLa cells. J Biol Chem, 1981. 256(15): p. 7691-4.

100. Otsuka, Y., N.L. Kedersha, and D.R. Schoenberg, Identification of a cytoplasmic complex that adds a cap onto 5'-monophosphate RNA. Mol Cell Biol, 2009. 29(8): p. 2155-67. 
101. Trotman, J.B., et al., RNA guanine-7 methyltransferase catalyzes the methylation of cytoplasmically recapped RNAs. Nucleic Acids Res, 2017. 45(18): p. 10726-10739.

102. Mukherjee, C., et al., Identification of cytoplasmic capping targets reveals a role for cap homeostasis in translation and mRNA stability. Cell Rep, 2012. 2(3): p. 674-84.

103. Krug, R.M., M.A. Morgan, and A.J. Shatkin, Influenza viral mRNA contains internal N6methyladenosine and 5'-terminal 7-methylguanosine in cap structures. J Virol, 1976. 20(1): p. 45-53.

104. Barbosa, E. and B. Moss, mRNA(nucleoside-2'-)-methyltransferase from vaccinia virus. Characteristics and substrate specificity. J Biol Chem, 1978. 253(21): p. 7698-702.

105. Barbosa, E. and B. Moss, mRNA(nucleoside-2'-)-methyltransferase from vaccinia virus. Purification and physical properties. J Biol Chem, 1978. 253(21): p. 7692-7.

106. Werner, M., et al., 2'-O-ribose methylation of cap2 in human: function and evolution in a horizontally mobile family. Nucleic Acids Res, 2011. 39(11): p. 4756-68.

107. Leung, D.W. and G.K. Amarasinghe, When your cap matters: structural insights into self vs non-self recognition of 5' RNA by immunomodulatory host proteins. Curr Opin Struct Biol, 2016. 36: p. 133-41.

108. Leiter, J., et al., Practical Synthesis of Cap-4 RNA. Chembiochem, 2020. 21(1-2): p. 265271.

109. Reolon, L.W., et al., Crystal structure of the Trypanosoma cruzi EIF4E5 translation factor homologue in complex with mRNA cap-4. Nucleic Acids Res, 2019. 47(11): p. 5973-5987.

110. Wei, C.M., A. Gershowitz, and B. Moss, 5'-Terminal and internal methylated nucleotide sequences in HeLa cell mRNA. Biochemistry, 1976. 15(2): p. 397-401.

111. Wei, C.M. and B. Moss, Nucleotide sequences at the N6-methyladenosine sites of HeLa cell messenger ribonucleic acid. Biochemistry, 1977. 16(8): p. 1672-6.

112. Chen, K., G.Z. Luo, and C. He, High-Resolution Mapping of N(6)-Methyladenosine in Transcriptome and Genome Using a Photo-Crosslinking-Assisted Strategy. Methods Enzymol, 2015. 560: p. 161-85.

113. Patil, D.P., B.F. Pickering, and S.R. Jaffrey, Reading $m(6) A$ in the Transcriptome: $m(6) A-$ Binding Proteins. Trends Cell Biol, 2018. 28(2): p. 113-127.

114. Edupuganti, R.R., et al., N(6)-methyladenosine $(m(6) A)$ recruits and repels proteins to regulate mRNA homeostasis. Nat Struct Mol Biol, 2017. 24(10): p. 870-878.

115. Huang, $\mathrm{H}$., et al., Recognition of RNA N(6)-methyladenosine by IGF2BP proteins enhances mRNA stability and translation. Nat Cell Biol, 2018. 20(3): p. 285-295.

116. Xiang, S., et al., N6-methyladenosine methyltransferase METTL3 promotes colorectal cancer cell proliferation through enhancing MYC expression. Am J Transl Res, 2020. 12(5): p. 1789-1806.

117. Barbieri, I., et al., Promoter-bound METTL3 maintains myeloid leukaemia by m(6)Adependent translation control. Nature, 2017. 552(7683): p. 126-131.

118. Huang, $\mathrm{H}$., et al., Histone $\mathrm{H3}$ trimethylation at lysine 36 guides m(6)A RNA modification co-transcriptionally. Nature, 2019. 567(7748): p. 414-419.

119. Scholler, E., et al., Interactions, localization, and phosphorylation of the $m(6)$ A generating METTL3-METTL14-WTAP complex. RNA, 2018. 24(4): p. 499-512.

120. Lin, S., et al., The m(6)A Methyltransferase METTL3 Promotes Translation in Human Cancer Cells. Mol Cell, 2016. 62(3): p. 335-345. 
121. Pendleton, K.E., et al., The U6 snRNA m(6)A Methyltransferase METTL16 Regulates SAM Synthetase Intron Retention. Cell, 2017. 169(5): p. 824-835 e14.

122. Shima, H., et al., S-Adenosylmethionine Synthesis Is Regulated by Selective N(6)-Adenosine Methylation and mRNA Degradation Involving METTL16 and YTHDC1. Cell Rep, 2017. 21(12): p. 3354-3363.

123. Warda, A.S., et al., Human METTL16 is a N(6)-methyladenosine (m(6)A) methyltransferase that targets pre-mRNAs and various non-coding RNAs. EMBO Rep, 2017. 18(11): p. 20042014.

124. Doxtader, K.A., et al., Structural Basis for Regulation of METTL16, an SAdenosylmethionine Homeostasis Factor. Mol Cell, 2018. 71(6): p. 1001-1011 e4.

125. Mendel, M., et al., Methylation of Structured RNA by the m(6)A Writer METTL16 Is Essential for Mouse Embryonic Development. Mol Cell, 2018. 71(6): p. 986-1000 e11.

126. Ruszkowska, A., et al., Structural insights into the RNA methyltransferase domain of METTL16. Sci Rep, 2018. 8(1): p. 5311.

127. Yeon, S.Y., et al., Frameshift Mutations in Repeat Sequences of ANK3, HACD4, TCP10L, TP53BP1, MFN1, LCMT2, RNMT, TRMT6, METTL8 and METTL16 Genes in Colon Cancers. Pathol Oncol Res, 2018. 24(3): p. 617-622.

128. Aoyama, T., S. Yamashita, and K. Tomita, Mechanistic insights into m6A modification of U6 snRNA by human METTL16. Nucleic Acids Res, 2020. 48(9): p. 5157-5168.

129. Nance, D.J., et al., Characterization of METTL16 as a cytoplasmic RNA binding protein. PLoS One, 2020. 15(1): p. e0227647.

130. Ma, H., et al., N(6-)Methyladenosine methyltransferase ZCCHC4 mediates ribosomal RNA methylation. Nat Chem Biol, 2019. 15(1): p. 88-94.

131. Wang, X., et al., N6-methyladenosine-dependent regulation of messenger RNA stability. Nature, 2014. 505(7481): p. 117-20.

132. Stoilov, P., I. Rafalska, and S. Stamm, YTH: a new domain in nuclear proteins. Trends Biochem Sci, 2002. 27(10): p. 495-7.

133. Zhang, Z., et al., The YTH domain is a novel RNA binding domain. J Biol Chem, 2010. 285(19): p. 14701-10.

134. $\mathrm{Xu}, \mathrm{C}$., et al., Structural basis for selective binding of m6A RNA by the YTHDC1 YTH domain. Nat Chem Biol, 2014. 10(11): p. 927-9.

135. Shi, H., et al., YTHDF3 facilitates translation and decay of N(6)-methyladenosine-modified RNA. Cell Res, 2017. 27(3): p. 315-328.

136. Wang, X., et al., N(6)-methyladenosine Modulates Messenger RNA Translation Efficiency. Cell, 2015. 161(6): p. 1388-99.

137. Huang, T., et al., YTHDF2 promotes spermagonial adhesion through modulating MMPs decay via m(6)A/mRNA pathway. Cell Death Dis, 2020. 11(1): p. 37.

138. Liu, N., et al., N(6)-methyladenosine-dependent RNA structural switches regulate RNAprotein interactions. Nature, 2015. 518(7540): p. 560-4.

139. Panneerdoss, S., et al., Cross-talk among writers, readers, and erasers of m(6)A regulates cancer growth and progression. Sci Adv, 2018. 4(10): p. eaar8263.

140. Mardakheh, F.K., et al., Global Analysis of $m R N A$, Translation, and Protein Localization: Local Translation Is a Key Regulator of Cell Protrusions. Dev Cell, 2015. 35(3): p. 344-57. 
141. Jia, G., et al., N6-methyladenosine in nuclear RNA is a major substrate of the obesityassociated FTO. Nat Chem Biol, 2011. 7(12): p. 885-7.

142. Zheng, G., et al., ALKBH5 is a mammalian RNA demethylase that impacts RNA metabolism and mouse fertility. Mol Cell, 2013. 49(1): p. 18-29.

143. Wei, J., et al., Differential $m(6) A, m(6) A m$, and $m(1) A$ Demethylation Mediated by FTO in the Cell Nucleus and Cytoplasm. Mol Cell, 2018. 71(6): p. 973-985 e5.

144. Zou, S., et al., N(6)-Methyladenosine: a conformational marker that regulates the substrate specificity of human demethylases FTO and ALKBH5. Sci Rep, 2016. 6: p. 25677.

145. Li, Y., et al., The dynamics of FTO binding and demethylation from the m(6)A motifs. RNA Biol, 2019. 16(9): p. 1179-1189.

146. Meyer, K.D. and S.R. Jaffrey, Rethinking m(6)A Readers, Writers, and Erasers. Annu Rev Cell Dev Biol, 2017. 33: p. 319-342.

147. Mauer, J. and S.R. Jaffrey, FTO, $m(6) A m$, and the hypothesis of reversible epitranscriptomic mRNA modifications. FEBS Lett, 2018. 592(12): p. 2012-2022.

148. Hess, M.E., et al., The fat mass and obesity associated gene (Fto) regulates activity of the dopaminergic midbrain circuitry. Nat Neurosci, 2013. 16(8): p. 1042-8.

149. Bartosovic, M., et al., N6-methyladenosine demethylase FTO targets pre-mRNAs and regulates alternative splicing and 3 '-end processing. Nucleic Acids Res, 2017. 45(19): p. 11356-11370.

150. Aas, A., et al., Nucleocytoplasmic Shuttling of FTO Does Not Affect Starvation-Induced Autophagy. PLoS One, 2017. 12(3): p. e0168182.

151. Zhang, X., et al., Structural insights into FTO's catalytic mechanism for the demethylation of multiple RNA substrates. Proc Natl Acad Sci U S A, 2019. 116(8): p. 2919-2924.

152. Song, H., et al., SFPQ Is an FTO-Binding Protein that Facilitates the Demethylation Substrate Preference. Cell Chem Biol, 2020. 27(3): p. 283-291 e6.

153. Engel, M., et al., The Role of $m(6) A / m-R N A$ Methylation in Stress Response Regulation. Neuron, 2018. 99(2): p. 389-403 e9.

154. Yoon, K.J., G.L. Ming, and H. Song, Epitranscriptomes in the Adult Mammalian Brain: Dynamic Changes Regulate Behavior. Neuron, 2018. 99(2): p. 243-245.

155. Huang, T., et al., Meclofenamic acid represses spermatogonial proliferation through modulating m(6)A RNA modification. J Anim Sci Biotechnol, 2019. 10: p. 63.

156. Ke, S., et al., m(6)A mRNA modifications are deposited in nascent pre-mRNA and are not required for splicing but do specify cytoplasmic turnover. Genes Dev, 2017. 31(10): p. 9901006.

157. Darnell, R.B., S. Ke, and J.E. Darnell, Jr., Pre-mRNA processing includes N(6) methylation of adenosine residues that are retained in $m R N A$ exons and the fallacy of "RNA epigenetics". RNA, 2018. 24(3): p. 262-267.

158. Meyer, K.D., et al., 5' UTR m(6)A Promotes Cap-Independent Translation. Cell, 2015. 163(4): p. 999-1010.

159. Annapoorna, P.K., et al., FTO: An Emerging Molecular Player in Neuropsychiatric Diseases. Neuroscience, 2019. 418: p. 15-24.

160. Liu, J., et al., Landscape and Regulation of m(6)A and m(6)Am Methylome across Human and Mouse Tissues. Mol Cell, 2020. 77(2): p. 426-440 e6. 
161. Akichika, S., et al., Cap-specific terminal N (6)-methylation of RNA by an RNA polymerase II-associated methyltransferase. Science, 2019. 363(6423).

162. Boulias, K., et al., Identification of the m(6)Am Methyltransferase PCIF1 Reveals the Location and Functions of m(6)Am in the Transcriptome. Mol Cell, 2019. 75(3): p. 631-643 e8.

163. Sun, H., et al., Cap-specific, terminal N(6)-methylation by a mammalian m(6)Am methyltransferase. Cell Res, 2019. 29(1): p. 80-82.

164. Pandey, R.R., et al., The Mammalian Cap-Specific m(6)Am RNA Methyltransferase PCIF1 Regulates Transcript Levels in Mouse Tissues. Cell Rep, 2020. 32(7): p. 108038.

165. Sikorski, P.J., et al., The identity and methylation status of the first transcribed nucleotide in eukaryotic mRNA 5' cap modulates protein expression in living cells. Nucleic Acids Res, 2020. 48(4): p. 1607-1626.

166. Cowling, V.H., CAPAM: The mRNA Cap Adenosine N6-Methyltransferase. Trends Biochem Sci, 2019. 44(3): p. 183-185.

167. Iyer, L.M., D. Zhang, and L. Aravind, Adenine methylation in eukaryotes: Apprehending the complex evolutionary history and functional potential of an epigenetic modification. Bioessays, 2016. 38(1): p. 27-40.

168. Bjorkbacka, H., et al., Plasma stem cell factor levels are associated with risk of cardiovascular disease and death. J Intern Med, 2017. 282(6): p. 508-521.

169. Claiborn, K.C., et al., Pcif1 modulates Pdx1 protein stability and pancreatic beta cell function and survival in mice. J Clin Invest, 2010. 120(10): p. 3713-21.

170. Hensel, J., et al., Patient Mutation Directed shRNA Screen Uncovers Novel Bladder Tumor Growth Suppressors. Mol Cancer Res, 2015. 13(9): p. 1306-15.

171. Klein, S., et al., The Phosphorylation of PDX-1 by Protein Kinase CK2 Is Crucial for Its Stability. Pharmaceuticals (Basel), 2016. 10(1).

172. Liu, A., B.M. Desai, and D.A. Stoffers, Identification of PCIF1, a POZ domain protein that inhibits PDX-1 (MODY4) transcriptional activity. Mol Cell Biol, 2004. 24(10): p. 4372-83.

173. Yunokuchi, I., et al., Prolyl isomerase Pin1 shares functional similarity with phosphorylated CTD interacting factor PCIF1 in vertebrate cells. Genes Cells, 2009. 14(9): p. 1105-18.

174. Fan, H., et al., PCIF1, a novel human WW domain-containing protein, interacts with the phosphorylated RNA polymerase II. Biochem Biophys Res Commun, 2003. 301(2): p. 37885.

175. Relier, S., et al., FTO-mediated cytoplasmic $m<s u p>6</$ sup $>A<s u b>m</$ sub $>$ demethylation adjusts stem-like properties in colorectal cancer cell. bioRxiv, 2020: p. 2020.01.09.899724.

176. Doxtader, K.A. and Y. Nam, Manipulation by Methylation: Garnishing mRNAs with m(6)Am. Mol Cell, 2019. 75(3): p. 417-418.

177. Schwartz, S., et al., Perturbation of $m 6 A$ writers reveals two distinct classes of $m R N A$ methylation at internal and 5' sites. Cell Rep, 2014. 8(1): p. 284-96.

178. Hirose, Y., et al., Human phosphorylated CTD-interacting protein, PCIF1, negatively modulates gene expression by RNA polymerase II. Biochem Biophys Res Commun, 2008. 369(2): p. 449-55. 
179. Del Valle Morales, D., et al., Inhibition of cytoplasmic cap methylation identifies 5' TOP $m R N A s$ as recapping targets and reveals recapping sites downstream of native $5^{\prime}$ ends. Nucleic Acids Res, 2020. 48(7): p. 3806-3815.

180. Berger, M.R., R. Alvarado, and D.L. Kiss, mRNA 5' ends targeted by cytoplasmic recapping cluster at CAGE tags and select transcripts are alternatively spliced. FEBS Letters, 2019. 593(7): p. 670-679.

181. Kiss, D.L., et al., Uncapped 5' ends of mRNAs targeted by cytoplasmic capping map to the vicinity of downstream CAGE tags. FEBS Lett, 2015. 589(3): p. 279-84. 